OPEN ACCESS

Edited by:

Andreas Rosenkranz, University of Chile, Chile

Reviewed by:

$T V V L N$ Rao,

Madanapalle Institute of Technology \&

Science (MITS), India

Max Marian,

Friedrich-Alexander-University

Erlangen-Nürnberg, Germany

${ }^{*}$ Correspondence:

Agnieszka M. Jastrzębska

agnieszka.jastrzebska@pw.edu.pl

Specialty section:

This article was submitted to

Nanoscience,

a section of the journal

Frontiers in Chemistry

Received: 24 March 2021

Accepted: 16 June 2021

Published: 29 June 2021

Citation:

Jakubczak $M$ and Jastrzębska AM (2021) A Review on Development of Ceramic-Graphene Based Nanohybrid

Composite Systems in

Biological Applications.

Front. Chem. 9:685014.

doi: $10.3389 /$ fchem.2021.685014

\section{A Review on Development of Ceramic-Graphene Based Nanohybrid Composite Systems in Biological Applications}

\author{
Michał Jakubczak and Agnieszka M. Jastrzębska * \\ Faculty of Materials Science and Engineering, Warsaw University of Technology, Warsaw, Poland
}

Graphene-based nanocomposites constitute an interesting and promising material for various applications. Intensive progress in the development of this group of materials offers an opportunity to create new systems useful for drinking water decontamination or other biotechnological applications. Nanohybrid structures of graphene-ceramic systems can be obtained using covalent graphene surface modification with nanoparticles (NPs) of ceramic and/or co-deposition of metals with selected morphology and chemistry. The present paper systematizes the associated bio-related knowledge and inspires future development of graphene/NPs systems. Emerging knowledge and unique research techniques are reviewed within designing the required nanocomposite structure and chemical composition, development and optimization of new methods of covalent surface modification of graphene with NPs as well as analysis of mechanisms governing the formation of covalent bonding. Further, innovative research tools and methodologies are presented regarding the adjustment of functionalities of materials used for the application in drinking water decontamination or biocidal composites. This study provides a comprehensive base for rational development of more complex, hybrid graphene-based nanomaterials with various bio-functionalities that can be further applied in industrial practice.

Keywords: graphene, hybrid structure, covalent modification, surface decoration, bioactivity, biosorption, composites

\section{INTRODUCTION}

Graphene belongs both to carbon and two-dimensional (2D) materials. The term "graphene" is accepted as a monolayer of carbon atoms with $\mathrm{sp}^{2}$ hybridization arranged in a honeycomb crystal lattice (Novoselov et al., 2004; Neto et al., 2006). Other relevant materials include the multilayer graphene (mostly labeled as graphene, graphene flakes, or graphene platelets), graphene oxide (GO) and reduced graphene oxide (RGO). It is agreed that graphene as well as its corresponding 2D structures are named the graphene-family nanomaterials and labeled as GMFs (Novoselov et al., 2004).

Since the game-changing discovery of graphene, the young field of GFMs has seen a fast-growing scientific interest. The rapid increase in research on GFMs also resulted in a significant demand for further industrial use with a growing market and a significant boost in sales. The forecast market is estimated at almost 195 million USD, reaching even 1.3 billion USD by 2023, with an average annual 


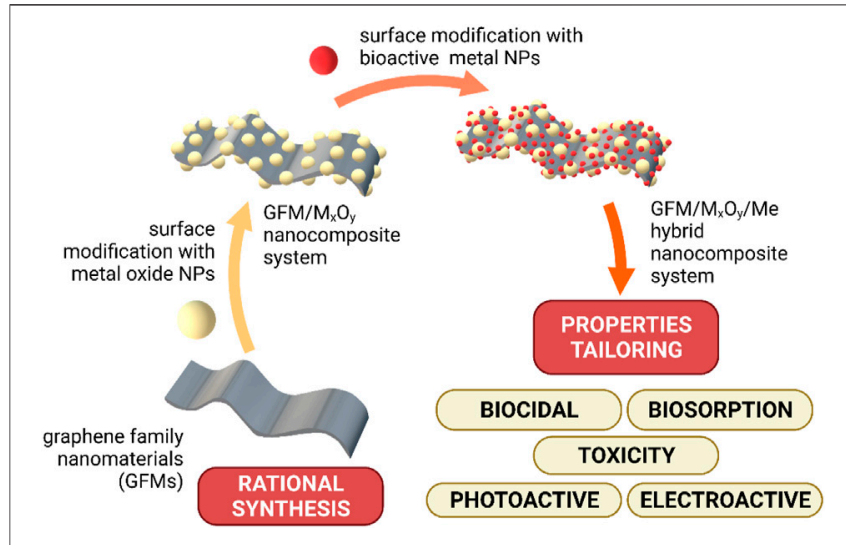

FIGURE 1 | Schematic of the areas of research covered by this work.

growth rate of $47.1 \%$ (McWilliams, 2013). Consequently, the GFMs field has been concentrated on exploitation of their unique characteristics in various fields, for instance, electronics (Castro Neto et al., 2009), mechanics (Frank et al., 2007), magnetism (Ominato and Koshino, 2013), charge carrier mobility (Pallecchi et al., 2014) as well as thermal conductivity (Pop et al., 2012). Many other interesting properties were also demonstrated (Zhang et al., 2011a) and a range of possible applications of GFMs were proposed as well (Shao et al., 2010; Zhang et al., 2011a; Kucinskis et al., 2013; Petrone et al., 2013; Garg et al., 2014; Yin et al., 2014). In this regard, there are comprehensive reviews available that discuss preparation of bulk structures with high density (Markandan et al., 2017) or functional nanocomposites (Ramírez et al., 2021). They discuss the addition of GFMs as a reinforcement agent to ceramic matrices and preparation of composites as well as potential of GFMs in functional applications such as energy production and storage, piezo and thermoelectrics or electromagnetic interference shielding. It is known that presence of GFMs in ceramic matrices largely improves their functional properties, but it can be fully explored only when homogenous dispersion of GFMs into ceramic matrix is provided. On the other side, preparation of GFMs surface-grafted and functionalized with a thin layer of ceramic material is not fully explored due to lack of complete understanding of mechanisms governing ceramic layer formation. Application of such structures in biological field is therefore hindered, due to lack of rational designing and synthesis of GFM-based ceramic.

Given the abovementioned knowledge gaps, this review papers summarizes and discusses the emerging knowledge and unique research techniques used toward development of graphene-based nanocomposites. In this regard, modification with ceramic nanoparticles $\left(\mathrm{Al}_{2} \mathrm{O}_{3} \mathrm{TiO}_{2}\right)$ and bioactive metals (noble metals etc.) appeared recently to be the most interesting in terms of e.g., bioactivity. Designing the required nanocomposite structure and chemical composition is highlighted together with development and optimization of new methods of GFMs covalent surface modification with NPs as well as analysis of mechanisms governing the formation of covalent bonding. Further, innovative research tools and methodologies are presented regarding the adjustment of material functionalities (biocidal, biosorption, toxicity, photoactive and electroactive) used for the application in drinking water decontamination or biocidal composites. These were summarized in Figure 1.

\section{BIOACTIVITY AND TOXICITY OF GFMs}

It is accepted that the hydrophobic nature of graphene limits its potential application (Wang et al., 2013). Such limitations however may be overcome due to the chemical oxidation of graphene, when the oxide form of graphene is formed. Highly oxidized GO is filled with lots of edges-located and oxygen-containing functional groups such as carboxyl, hydroxyl and epoxy (Song et al., 2013) (see Figure 2). On the other hand, reduced graphene oxide obtained by thermal and chemical reduction methods, contains much less oxygen-based functional groups. The presence of these groups, their number or absence determines the properties of GMFs, and therefore their functionality (Song et al., 2013; Olborska et al., 2020). Figure 3 shows Scanning Electron Microscopy (SEM) images of morphologies of the studied GFMs. GFMs differ not only in the case of surface chemistry but also in structural properties such as morphology, size, and shape of the flakes as well as their thickness. Despite having similar chemical structures, both single and multilayer graphene possesses different morphologies. As clearly shown in work (Sarikaya et al., 2020), multilayer graphene has a very wrinkled, cotton flower-like morphology, while the surface of single flakes of graphene is basically flat. Differences were noticed not only in the case of morphology, but also dimensions, as for multilayer graphene the lateral size was about $5 \mathrm{~nm}$, while for single flakes it was less than half of this value. In work (Gomez et al., 2020) authors also observed wrinkled structure for graphene oxide and reduced graphene oxide with the thickness in the range of $1 \mathrm{~nm}$. The lateral size however was substantially bigger, and as they found out, it was about $20-30 \mu \mathrm{m}$ for both GO and RGO. As further studies revealed, GO has a tendency to retain smooth, slightly wrinkled surface, while RGO sheets stacks and aggregates with the creation of rough and pointed edges were observed (Gurunathan et al., 2012).

Recent studies also suggest the interesting biological properties of GFMs. For instance, it was demonstrated that GO and graphene flakes interact with many biomolecules. Consequently, they may pose an impact on various biological systems (Novoselov et al., 2004; Radic et al., 2013). The rapidly growing volume of literature on the subject shows that the development of GFMs-based bioactive nanocomposite systems shows both opportunities and challenges ( $\mathrm{Li}$ et al., 2008). The important aspect to analyze is the potential toxicity of GFMs towards various living organisms and the relevant impact of surface modifications. Figure 4 shows a constellation of the observed toxic effects of GFMs in terms of their production methods. There is no doubt that the bioactivity of individual GFMs may greatly vary. Nevertheless, it is closely associated with the GFMs production method and their possible surface modification. This in turn determines both their morphology and physicochemical properties. 

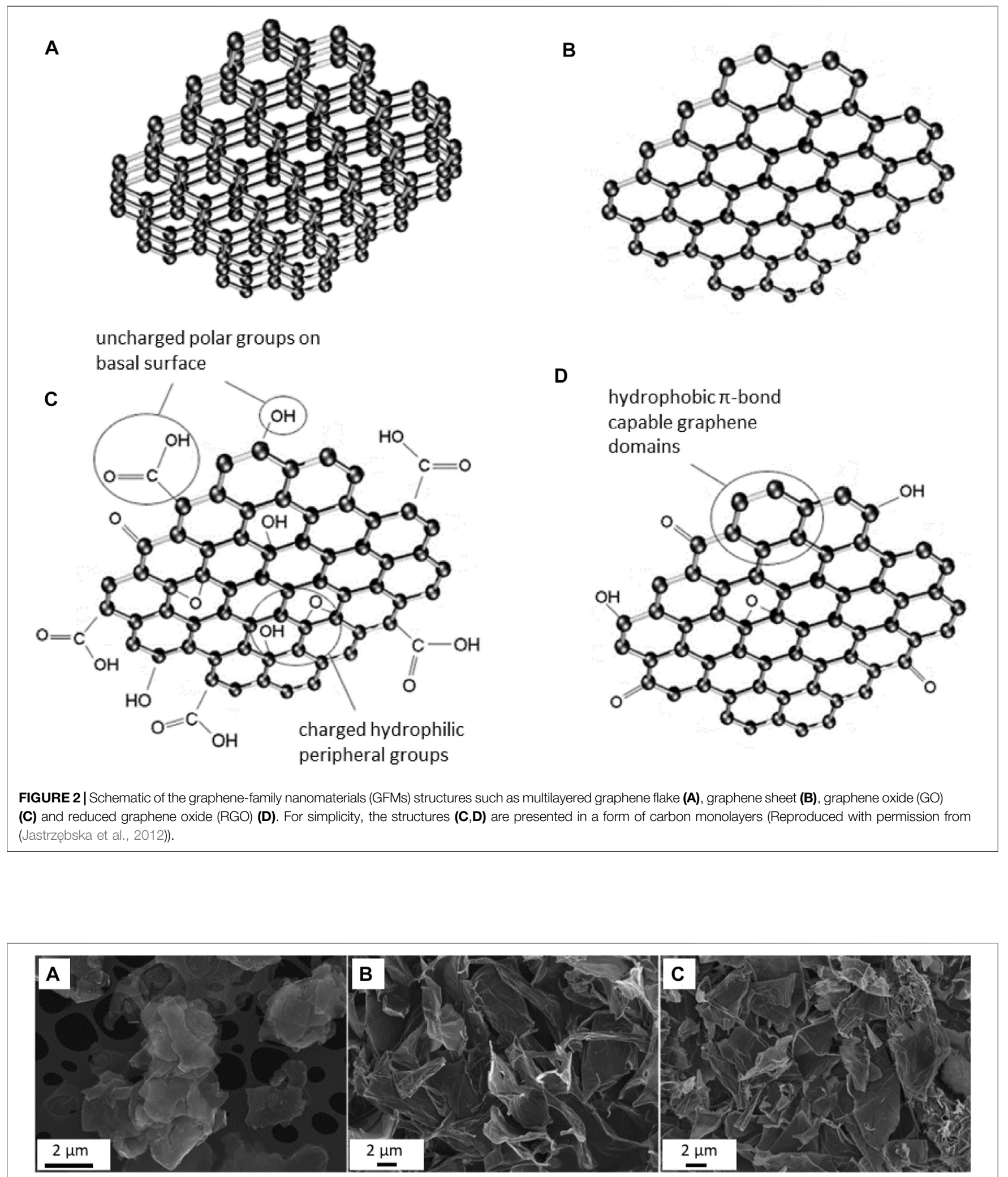

FIGURE 3 | Comparison of morphologies of graphene flakes (A), GO (B) and RGO (C) using SEM analysis (Reproduced with permission from (Jastrzębska et al., 2017a)). 


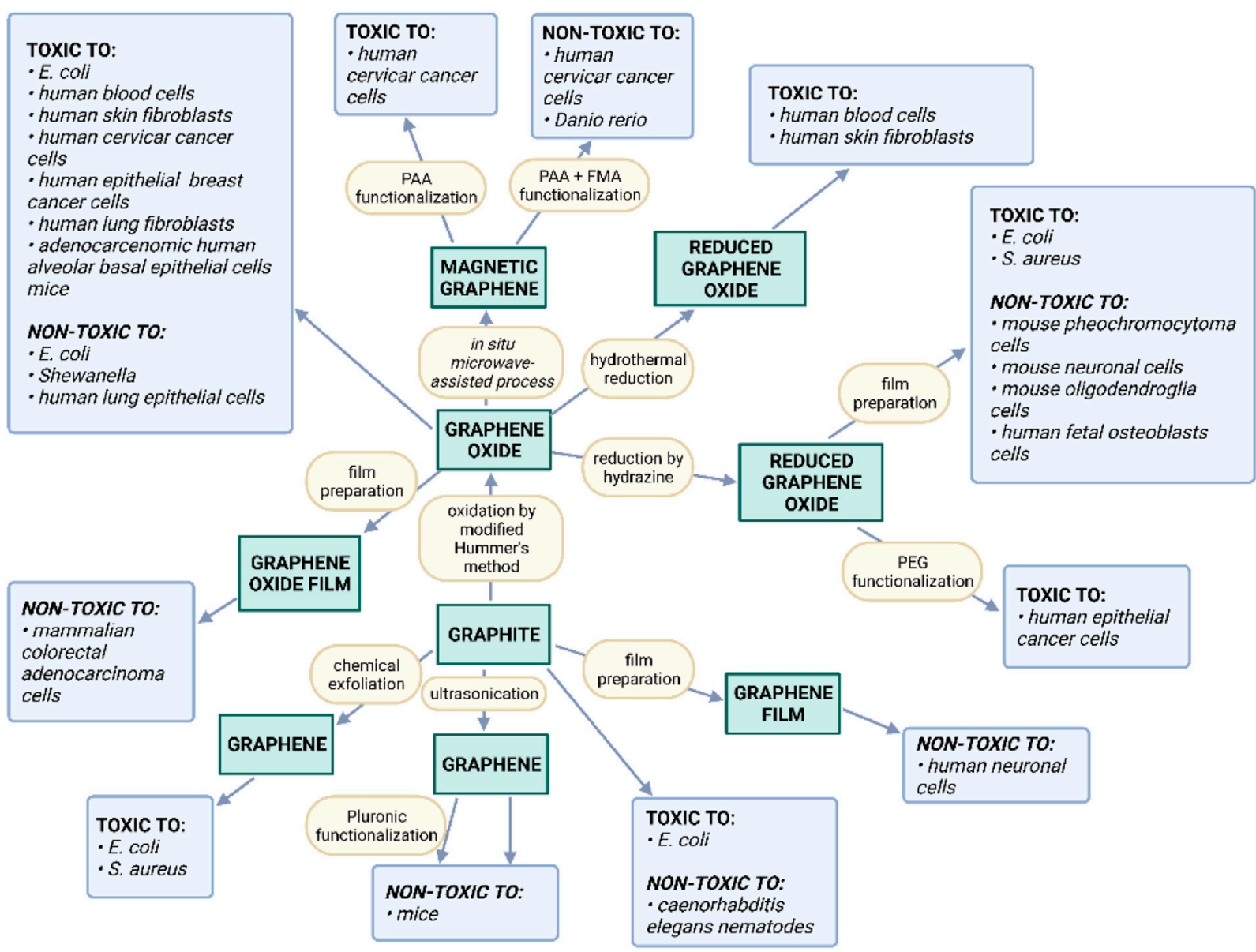

FIGURE 4 | Summary of the observed toxic effects of GFMs in terms of their production methods and the impact of possible functionalization (Reproduced with permission from (Jastrzębska et al., 2012)).

\section{Biocidal Characteristics of GFMs}

Antibacterial properties of different representatives of GFMs also suggest their application potential in biocidal products (Akhavan and Ghaderi, 2010; Hu et al., 2010). While considering their application in water filtration systems, the most significant is their interaction with bacterial cells (Akhavan and Ghaderi, 2010; Hu et al., 2010; Zhang et al., 2011a). The most popular GFMs studied in this context are multilayer graphene flakes, GO and RGO. It is demonstrated that RGO exhibits higher antimicrobial activity towards the Escherichia coli and Staphylococcus aureus strains in comparison to GO ( $\mathrm{Hu}$ et al., 2010). The assumed toxicity mechanism is the result of direct contact of cells with GFM, whereby $E$. coli shows more resistance compared to $S$. aureus. Other results suggest the antimicrobial activity of GO against E. coli and S. aureus and a mechanism of toxicity stemming from the contact damage to the cell wall ( $\mathrm{Hu}$ et al., 2010). Further studies indicate stronger toxic effects of GO than RGO towards E. coli and the oxidative stress is mostly indicated as an additional toxicity mechanism (Liu et al., 2011). Apart from these, three other studies showed a lack of bactericidal effect of graphene flakes (Zhang et al., 2011a) and GO (Wang et al., 2011; Akhavan and Ghaderi, 2012) towards bacterial cells. There was no reduction of bacterial growth in presence of selected GFMs (Akhavan and Ghaderi, 2010; Hu et al., 2010; Liu et al., 2011). Therefore, a follow-up study thoroughly analyzed these issues and showed a significant impact of the methods of production of individual GFMs on their toxic characteristics (also against bacteria) (Jastrzębska et al., 2012).

Given the abovementioned information, GO is the most interesting 2D nanomaterial in terms of potential bioactivity, including both biocidal properties (Akhavan and Ghaderi, 2010; Hu et al., 2010; Kurantowicz et al., 2015) and biocompatibility (non-biocidal features) (Zhang et al., 2011a; Wang et al., 2011). Therefore, three representatives of GFMs such as graphene flake, GO and RGO were compared in (Jastrzębska et al., 2017b). At a first glance, it becomes clear that the morphology of graphene flakes and GO together with RGO may play a key role in occurring the bio-nano interactions. However, obtained results indicate other important factors governing the toxicity towards bacteria. Apart from the morphology, these are mostly a type of bacteria cells. Indeed, the absence of bactericidal activity of GO was demonstrated in the presence of E. coli, S. aureus, Bacillus sp. and Sarcina (Jastrzębska et al., 2017b), which is consistent with other works (Zhang et al., 2011a; Wang et al., 2011). 


\section{Biosorption Properties of GFMs}

Another interesting biological research approach assumes that the produced GFMs could be applicable in drinking water filtration and therefore, should exhibit both biocidal and biosorption properties towards bacteria cells. The best choice of GFM should be based on not only antibacterial effects, but also the biosorption properties. Many carbon-based nano-sorbents are widely used in water decontamination from various undesirable inorganic and organic substances. Compared to their macroscopic counterparts, the advantage of nanosorbents in this field is a significantly larger specific surface area. The effective adsorption properties were already proved for nonmodified carbon nanotubes (Li et al., 2003; Li et al., 2004), carbon nanotubes surface-modified with inorganic NPs (Peng et al., 2005), carbon fibers (Mangun et al., 2001) as well as nanoporous ceramics (Yantasee et al., 2003).

A recent study (Jastrzębska et al., 2017b) compared the biosorption characteristics of graphene flakes, GO and RGO. It also confirmed the applicability of zeta $(\zeta)$ potential in the experimental analysis of GFMs' biosorption properties. It is accepted that the electrostatic charge present on the surface of various materials (determined experimentally as $\zeta$ ) is the key factor for attracting bacteria towards the surface (Marshall et al., 1971; Bitton and Marshall, 1980; Mozes et al., 1987; MartinezMartinez et al., 1991). To date, extensive research has been conducted on the occurrence of the electric double layer and its linking directly to the zeta potential and the subsequent adsorption of bacteria cells onto the solid surface (Fletcher and Loeb, 1979; Ellwood et al., 1982; Scholl et al., 1990; Gannon et al., 1991; Krekeler et al., 1991; Marshall, 1992; Huysman and Verstraete, 1993). It is noted that these studies concerned, to a significant extent, the interaction between the surface of inorganic material and the bacteria and pointed to the necessity of an individual approach towards understanding this phenomenon due to differences in the chemical composition of materials' surface (Fletcher and Loeb, 1979; Ellwood et al., 1982; Scholl et al., 1990; Gannon et al., 1991; Krekeler et al., 1991; Marshall, 1992; Huysman and Verstraete, 1993). Yet, there is no doubt that the phenomenon of biosorption is still difficult to describe and to examine experimentally since the structure of and surface features of living organisms are much more varied and complex than the surface of inorganic materials (Kłodzińska et al., 2010). For instance, it was reported that the electrostatic charge that forms on the cell wall surface may be the result of dissociation of inorganic functional groups such as carboxylic or amino acid exposed to the aquatic environment (Dikusar, 1940; Santoro and Stotzky, 1968; van Loosdrecht et al., 1987).

What is more, the surface of GO hydrophilic is highly negative $\zeta$ which allows for the preparation of stable water dispersions ( $\mathrm{Li}$ et al., 2008). It is explained by the presence of electrostatic repulsion which allows the preparation of stable water dispersions of GO. Consequently, it becomes clear that the material-to-cell interactions cannot be governed only by electrostatic interactions. However, the very first studies did not concern the processes of biosorption. A later study (Kurantowicz et al., 2015) demonstrated the changes in the $\zeta$ of GFMs due to their interaction with bacteria. Thus, taking into

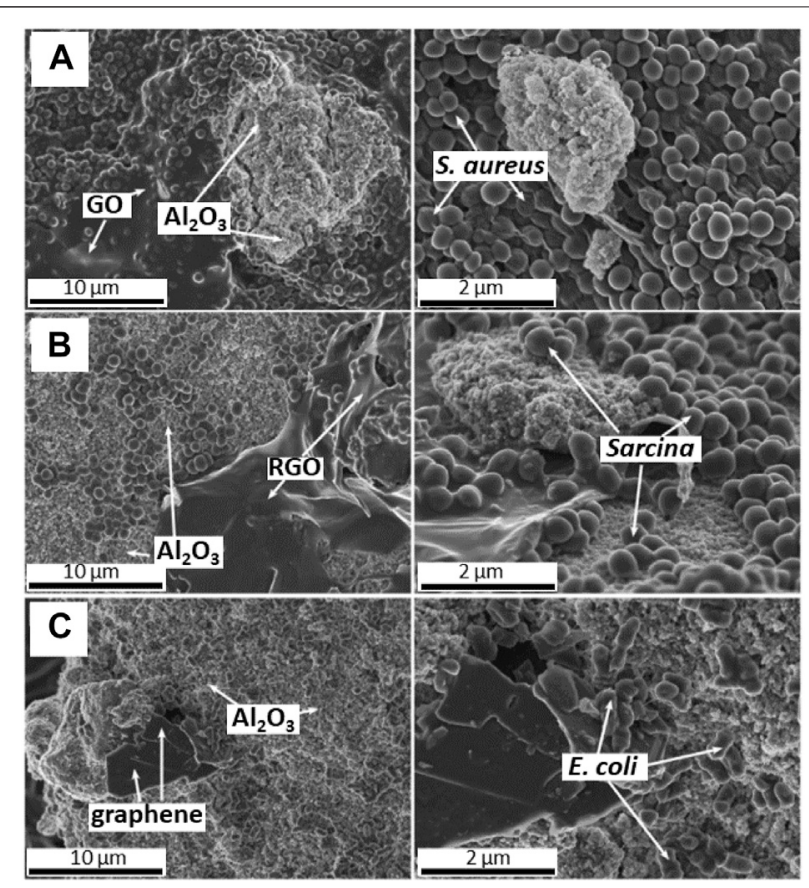

FIGURE 5 | SEM images of competitive biosorption between nano$\mathrm{Al}_{2} \mathrm{O}_{3}$ and $\mathrm{GO}$ towards $S$. aureus cells (A), RGO towards Sarcina cells (B) and graphene flakes towards $E$. coli cells (C) (Reproduced with permission from (Jastrzębska et al., 2017b) with minor changes).

account the state of knowledge on biosorption, it was important to carry out a thorough investigation of the biosorption efficiency of GFMs to different bacteria using $\zeta$ parameter. It was demonstrated that the biosorption efficiency of each GFM toward E. coli, S. aureus, Bacillus sp. and Sarcina species is different and depends on the type of strain. The zeta potential of E. coli and $S$. aureus strains after their adsorption on the GFM surface did not undergo many changes (Jastrzębska et al., 2017b). In general, carbon materials are considered to be the primary food source for bacteria (carbon source) (Fonte et al., 2013). While following the studies (Soni et al., 2008) and (Bruinsma et al., 2001), it is assumed that bacteria should not change their $\zeta$ as a result of adsorption, but retain their natural (healthy) $\zeta$ value, determining their good viability. Finally, this assumption was confirmed only for E. coli and $S$. aureus strains. Different results were obtained for the Bacillus $s p$. strain, for which $\zeta$ changed its value from $-26 \mathrm{mV}$ to $-5 \mathrm{mV}$ due to the adsorption, compared to the pure cell suspension. Such a result indicates a lack of adsorption and transformation of Bacillus sp. cells into the state of nutrition deficiency following the assumptions made in other studies (Bruinsma et al., 2001; Soni et al., 2008).

Another study considered GO flakes using Fourier transform infrared (FTIR) and Raman investigations (Jastrzębska and Olszyna, 2015). It confirmed that the GO' surface functional groups (i.e., $\mathrm{C}=\mathrm{O}, \mathrm{O}=\mathrm{C}-\mathrm{OH}$ or $\mathrm{C}-\mathrm{OH}$ ) take part in amphoteric reactions resulting in the formation of surface charge and zeta potential. It also showed a strong association of $-\mathrm{COOH}$ and $-\mathrm{OH}$ 
groups leading to the formation of higher-level (e.g., ionic doublets, triplets), neutral or charged associated molecules. The obtained results excluded the participation of $\mathrm{C}=\mathrm{O}$ groups in amphoteric reactions, contrary to $-\mathrm{COOH}$ and $-\mathrm{OH}$ groups.

Further comparison of biosorption characteristics of the GFMs considered the presence of aluminum nano-oxide (nano- $\mathrm{Al}_{2} \mathrm{O}_{3}$ ) as a competitive factor (Jastrzębska et al., $2017 \mathrm{~b})$. It was found that the nano- $\mathrm{Al}_{2} \mathrm{O}_{3}$ exhibited much stronger biosorption properties in comparison to $\mathrm{GO}$ and often better than other investigated GFMs. The SEM analysis allowed observing the majority of bacterial cells (e.g., the S. aureus strain) preferred to colonize the GO surface in the presence of nano- $\mathrm{Al}_{2} \mathrm{O}_{3}$ (Figure 5A). Another case showed Sarcina cells preferring the colonize of nano- $\mathrm{Al}_{2} \mathrm{O}_{3}$ in contrary to RGO (Figure 5B). Also, E. coli tended to colonize mainly the surface of nano- $\mathrm{Al}_{2} \mathrm{O}_{3}$ while graphene flakes were present in the suspension (Figure $5 \mathbf{C}$ ).

\section{ON THE RGO/AI ${ }_{2} \mathrm{O}_{3}$ NANOCOMPOSITE SYSTEM}

\section{Synthesis Approaches}

The production of nanocomposite materials via modification of GFMs surface with NPs is an interesting research topic. Such an approach can be applied to developing innovative water filtration technologies. The GFMs representative that appears as the most interesting in this regard is the GO due to its stronger biosorption characteristics as compared to graphene or RGO. The relevant literature points to the possibility of obtaining graphene nanocomposites using various methods of surface decoration, whereby methods that allow for the covalent attachment of NPs are the most perspective for avoiding NPs' leakage. This advantage resulted in large interest in the covalent modification of GFMs surface with ceramics nanoparticles (Zhang et al., 2010; Shen et al., 2010; Wu et al., 2010). Obtaining a non-agglomerated welldefined core-shell structure of $2 \mathrm{D}$ nanocomposite flakes is a great challenge because it requires the development of techniques for controlling material morphology and structure. Yet, the first attempt to obtain graphene/NPs in a form of single 2D flakes surface-modified with a thin covalent NPs layer has considered pure graphene flakes, but without a breakthrough. Importantly, the aim is to obtain an adequate and strong bonding between the GFM surface and NPs with a sustainable approach. Meanwhile, it was observed that GO offers the greatest possibilities of surface modification thanks to the presence of oxygen-containing surface functional groups. In this regard, the GO was soon accepted as the most promising material for such a purpose. Consequently, surface-modifications of GO using wet (involving water) and sol-gel methods became highly explored. For instance, $\mathrm{RGO} / \mathrm{SiO}_{2}$ nanocomposite with a thin $\mathrm{SiO}_{2}$ layer was obtained for use as transparent conductive tracers (Watcharotone et al., 2007). Another study presented a solid $\mathrm{RGO} / \mathrm{Al}_{2} \mathrm{O}_{3}$ nanocomposite for catalytic hydrodesulfurization (Jiwei et al., 1987). The synthesis method consisted of wet hydrolysis of boehmite in an acidic environment, GO modification, and subsequent heat treatment.
Based on previous results, it was found that $\mathrm{Al}_{2} \mathrm{O}_{3}$ nanoparticles should be primarily used as the modifier of bioactive properties of GFMs (Jastrzębska et al., 2017b). The objective was to obtain a material that would combine the beneficial bioactive properties of both $\mathrm{GO}$ and nano- $\mathrm{Al}_{2} \mathrm{O}_{3}$. The most important achievement in this field is the development of a novel $d r y$ (without using water) sol-gel method for obtaining a highly demanding system of graphene covalently modified with aluminum oxide nanoparticles (Jastrzębska et al., 2015). The method involves a reactive metal-organic aluminum compound (triethylaluminium) as the reagent and source of $\mathrm{Al}$ in a water and oxygen-free environment (Jastrzębska et al., 2015). The analysis of the final powdered product confirmed that $\mathrm{Al}_{2} \mathrm{O}_{3}$ nanoparticles covered uniformly the RGO surface, while the GO was reduced to RGO (Jastrzęska et al., 2016a). During the process, triethylaluminium reacts with terminal functional groups (i.e., $\mathrm{C}=\mathrm{O}, \mathrm{O}=\mathrm{C}-\mathrm{OH}, \mathrm{C}_{2} \mathrm{O}, \mathrm{C}-\mathrm{OH}$ ) present on the surface of GO. As a result, oxygen is being transferred from the GO surface to the structure of the emerging alumoxane precursor. This effect is called the in situ reduction of GO to RGO. In the next stage, organic precursor groups are involved in the formation $\mathrm{Al}_{2} \mathrm{O}_{3}$ crystal structure. As a result, the $\mathrm{RGO} / \mathrm{Al}_{2} \mathrm{O}_{3}$ nanocomposite is forming via the evaporation of hexane and precursor thermal decomposition.

On the other hand, the new $d r y$ sol-gel method for $\mathrm{RGO} / \mathrm{Al}_{2} \mathrm{O}_{3}$ nanocomposite synthesis turned out to be troublesome because of the high reactivity of the $\mathrm{Al}_{2} \mathrm{O}_{3}$ precursor and the need for an inert environment of the process. The inert environment requires the use of complicated equipment for operation in an argon protective atmosphere. Also, the potential risk of explosion or spontaneous reactant ignition was assessed as problematic from the upscaling point of view. Thus, it soon became necessary to develop a safer as well as more sustainable, simplified, and userfriendly method to produce the $\mathrm{RGO} /$ metal oxide nanocomposites. The modification of $\mathrm{RGO}$ with $\mathrm{Al}_{2} \mathrm{O}_{3}$ nanoparticles using less reactive and safer reagents constitutes yet another significant contribution to the development of the $\mathrm{RGO} / \mathrm{Al}_{2} \mathrm{O}_{3}$ nanocomposites (Jastrzęsska et al., 2016a). The newly developed process of covalent GO surface modification with $\mathrm{Al}_{2} \mathrm{O}_{3}$ nanoparticles was called the simplified sol-gel method (Jastrzębska et al., 2016a). It utilizes an alumoxane $\mathrm{Al}(\mathrm{OR})_{3}$ compound ( $\mathrm{R}$ is an alkyl substituent) as the precursor for $\mathrm{Al}_{2} \mathrm{O}_{3}$. What's important, in case of the application of aluminium alkoxy compounds as reagents, alcohols can be used as solvents. The new method of $\mathrm{RGO} / \mathrm{Al}_{2} \mathrm{O}_{3}$ nanocomposites synthesis allowed to obtaining similar results of material morphology and properties, as compared to a previous study (Jastrzębska et al., 2015). The FTIR and Raman analysis of the intermediate product (precursor) before thermal decomposition confirmed the presence of covalent bonding between $\mathrm{Al}$ and $\mathrm{O}$ atoms at the interface between $\mathrm{GO}$ surface and alumoxane. In particular, the $\mathrm{C}=\mathrm{O}\left(1730 \mathrm{~cm}^{-1}\right), \mathrm{C}-\mathrm{O}-\mathrm{C}$ $\left(1280 \mathrm{~cm}^{-1}\right)$ and $\mathrm{C}-\mathrm{O}\left(1225 \mathrm{~cm}^{-1}\right)$ groups formed a covalent Al-O bonding (Jastrzębska et al., 2016a). The intensity of the FTIR signals corresponding to these groups was significantly decreased, while the signals corresponding to the Al-O bonds appeared in the FTIR spectra. The Raman analysis showed no 


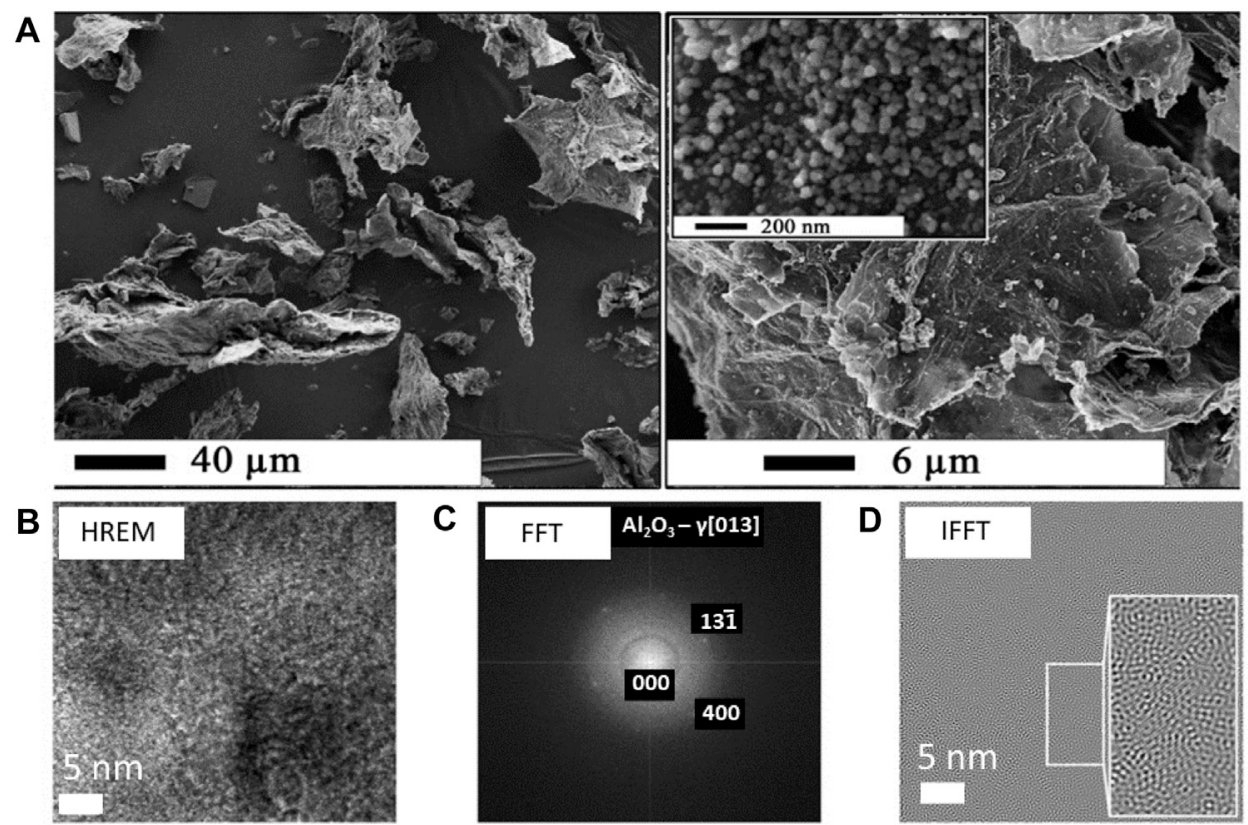

FIGURE 6 | SEM and TEM analysis of the $\mathrm{RGO} / \mathrm{Al}_{2} \mathrm{O}_{3}$ nanocomposite morphology (A) and structure (B-D) obtained via simplified sol-gel method (Reproduced with permission from (Jastrzębska et al., 2016a) with minor changes).

changes in the hexagonal structure of graphene within mutual intensities of " $D$ " and " $G$ " signals, characteristic for GO. While using the thermogravimetric analysis (TGA) combined with FTIR, a detailed analysis of the process of thermal decomposition of the precursor into the final product (the $\mathrm{RGO} / \mathrm{Al}_{2} \mathrm{O}_{3}$ nanocomposite, see Figure 6) was carried out. On this basis, the optimum temperature of thermal decomposition was determined (at $300^{\circ} \mathrm{C}$ ) (Jastrzębska et al., 2016a), which allowed for conducting the complete process of thermal decomposition (production of the $\mathrm{RGO} / \mathrm{Al}_{2} \mathrm{O}_{3}$ nanocomposite) while maintaining the graphene structure (no hexagonal structure degradation). The further X-ray photoelectron spectroscopy (XPS) analysis also confirmed the occurrence of in situ GO reduction to $\mathrm{RGO}$. The $\mathrm{Al}_{2} \mathrm{O}_{3}$ nanoparticles were, therefore, undoubtedly attached to RGO via a covalent bonding.

Further studies concerned the optimization process of nanocomposites prior to upscaling. It was most important to find the lowest possible agglomeration of $\mathrm{RGO} / \mathrm{Al}_{2} \mathrm{O}_{3}$ nanocomposite flakes and the most homogeneous coverage of the RGO surface. It was demonstrated that the synthesis parameters have a decisive influence on the morphology and physicochemical properties of the $\mathrm{RGO} / \mathrm{Al}_{2} \mathrm{O}_{3}$ nanocomposites (Jastrzębska et al., 2017b). An important result is that too intensive heat treatment leads to the agglomeration of $\mathrm{Al}_{2} \mathrm{O}_{3}$ nanoparticles on the edges of RGO flakes. It should be noted, however, that while this phenomenon cannot be completely eliminated, it can be controlled by the appropriate selection of both synthesis and heat treatment parameters of the intermediate product. The presented results confirmed that despite the occurrence of less wettability (Wang et al., 2008), RGO may be also applicable for surface modification with ceramic oxides due to the presence of the residual quantities of functional groups on the surface.

Other works concerned a newly developed solvothermal method, which was employed for the first time to fabricate $\mathrm{RGO} / \mathrm{Al}_{2} \mathrm{O}_{3}$ nanocomposite in a form of $\mathrm{Al}_{2} \mathrm{O}_{3}$ nanorods covering the GO surface (Ikram et al., 2018). Further reduction of GO to RGO was obtained by further calcination treatment, which was followed by hot pressing to obtain hybrid samples. It has been noted that different concentrations of RGO could be obtained with varying times of calcination, however, the enhanced crystallinity was achieved by increasing calcination temperature. The solid $\mathrm{RGO} / \mathrm{Al}_{2} \mathrm{O}_{3}$ samples were characterized by enhanced electrical, mechanical, thermal, and physical properties and therefore both calcination and hot pressing are beneficial for the formation of $\mathrm{Al}_{2} \mathrm{O}_{3}$ nanostructures and $\mathrm{GO} /$ RGO transformation. The enhanced mechanical properties of $\mathrm{RGO} / \mathrm{Al}_{2} \mathrm{O}_{3}$ were associated with covalent-type chemical interactions and efficient mass diffusion between RGO and $\mathrm{Al}_{2} \mathrm{O}_{3}$ in the grain boundary regions, while improved physical properties were attributed to the well-aligned, elongated and fine nanorod morphology of $\mathrm{Al}_{2} \mathrm{O}_{3}$. The authors also observed enhancement of the electrical conductivity due to the more availability of surface electrons coming from RGO. The restoration of the $\mathrm{sp}^{2} \mathrm{C}-\mathrm{C}$ bonds and cross-linking between RGO sheets additionally caused the improvement of electrical properties. It is also noted that the heat treatment was crucial in both cases.

While considering the incorporation of RGO to the alumina matrix, the important aspect to consider is controlling the growth of the $\mathrm{Al}_{2} \mathrm{O}_{3}$ grain by the presence of graphene sheets. The $\mathrm{Al}_{2} \mathrm{O}_{3}$ grains size was remarkably reduced due to the presence of 
graphene sheets (He et al., 2009). It was observed, however, that the presence of alumina particles enhances the milling efficiency, which was used to prepare investigated samples. It was also shown that the $0.5 \mathrm{wt} \%$ addition of $\mathrm{GO}$ to $\mathrm{Al}_{2} \mathrm{O}_{3}$ matrix via powder metallurgy and spark plasma consolidation (SPS) allow for a significant increase (almost 35\%) of the fracture toughness for $\mathrm{GO} / \mathrm{Al}_{2} \mathrm{O}_{3}$ composites in comparison to pure alumina sinters (Cygan et al., 2017). Also, in this case, a good interface between the reinforcement and the matrix was revealed using TEM. Therefore, the expected outcome is a significant improvement of fracture toughness (60\%) for the $\mathrm{RGO} / \mathrm{Al}_{2} \mathrm{O}_{3}$ composites (Wozniak et al., 2017). Mechanical milling, as well as solutionbased synthesis, were combined and employed in recent work (Kim et al., 2018) to achieve $\mathrm{RGO} / \mathrm{Al}$ nanocomposites in the so called mechano-chemical process. In the first step, $\mathrm{Al}$ grains are milled into flakes with the increased surface area. Then, they are coated with GO flakes via a solution process with the assistance of polyvinyl alcohol for the formation of hydroxyl groups. In the last step, the composite powder is subjected to drying, annealing, milling, and consolidation. The large surface area is provided by mechanical milling and an overall improved dispersion of RGO. This adjusts the mechanical and thermal properties of the nanocomposite.

In recent years, bio-inspired nanocomposites have caught scientists' attention due to their sustainability and robustness. In work (Chen et al., 2021), the monolithic $\mathrm{RGO} / \mathrm{Al}_{2} \mathrm{O}_{3}$ nanocomposites with fibrous bamboo-like architecture were fabricated for improved tribological performance and wear mechanisms. The materials were obtained by a coating of $\mathrm{Al}_{2} \mathrm{O}_{3}$ fiber cells with $\mathrm{GO}$ via physical adsorption. The preforms were then rearranged by the molding process. The last step involved removing the organic binder in a high vacuum and subsequent hot-pressing to obtain the final structure. The presence of RGO boundaries between $\mathrm{Al}_{2} \mathrm{O}_{3}$ fiber cells resulted in superior friction reduction and wear resistance, with stable friction coefficients. Fracture responses of bioinspired RGO/ $\mathrm{Al}_{2} \mathrm{O}_{3}$ fibrous monolithic ceramic were also investigated in work (Chen et al., 2020a). The investigated nanocomposite was characterized by progressive plastic failure behavior, excellent damage tolerance and high structural reliability due to complex hierarchical architectures with several different levels. The obtained structure enabled crack deflection, delamination and redistribution of load, which enhanced fracture resistant behavior.

\section{Potential Environmental Implications}

Simultaneously with research on the applicability of graphene nanocomposites in the processes of biosorption, the study (Jastrzębska and Olszyna, 2015) explores the threats arising from the possibility of leaking of the developed nanocomposites in purified water and the relevant impact after further spreading into the environment. At this stage, it was necessary to determine the potential risks associated with the production of nanocomposites on an industrial scale and their use in consumer products. An essential outcome of the study (Jastrzebska and Olszyna, 2015) is the analysis of the probable distribution and transport paths of graphene nanocomposites in the environment and the associated threats for particular ecosystems. The analysis carried out on exemplary $\mathrm{RGO} / \mathrm{Al}_{2} \mathrm{O}_{3}$ nanocomposite incorporated elements of the life cycle assessment (LCA) concerning threats associated with the use of the RGO/ $\mathrm{Al}_{2} \mathrm{O}_{3}$ in drinking water filtration. Figure 7 presents a diagram that analyses the potential transport pathways of the developed $\mathrm{RGO} / \mathrm{Al}_{2} \mathrm{O}_{3}$ nanocomposites into the natural environment. The assumed case-study scenario involved the environmental fate of the $\mathrm{RGO} / \mathrm{Al}_{2} \mathrm{O}_{3}$ after its leakage from a manufacturing plant (filtration material production), transportation to another plant, storage, leakage from filtration material, dusting, and storage of the used filter as solid waste. In the case of threats associated with leaching, it was observed that the sludge can be used for agricultural soils, disposed of as solid waste in landfills, or burned. The potential risk also depends on whether the RGO/ $\mathrm{Al}_{2} \mathrm{O}_{3}$ interacts with the various environmental components such as soil, sediments, fresh and groundwater resources, wastewater and marine environment. The analysis pointed out that the exposure paths depend not only on the fate and transfer pathways of the $\mathrm{RGO} / \mathrm{Al}_{2} \mathrm{O}_{3}$ in the environment but also on the factors affecting its transformation (aggregation, limiting factors, environmental conditions). In this regard, Figure 8 additionally shows the schematic summary of the most important methods and techniques that can be used as the so called selection keys for the characterization of GFMs in terms of targeted research on their bioactive properties and potential toxicity.

In view of the potential bioactive properties of GFMs, special attention should be given to the selection of the dispersion media (Jastrzębska and Olszyna, 2015). It is concluded that such properties should be examined in conditions as close to the natural environment as possible, which is currently being applied in the research on other types of nanomaterials (Keller et al., 2010). The issue of the significance of the zeta potential analysis is also a matter of interest (Jastrzębska and Olszyna, 2015). The theory of the electric double layer may be successfully used in the case of graphene oxide (Li et al., 2008) mainly on account of the hydrophilic properties of its surface. Thanks to this, GO flakes can form a stable colloidal dispersion, which contrasts with graphene and reduced graphene oxide that possess water-repellent surfaces (Stankovich et al., 2006; Stankovich et al., 2007). It is necessary to check the $\zeta$ of $\mathrm{RGO} /$ metal oxide suspensions to enable better anticipation of the processes of aggregation and deposition that are responsible for further material transfer in the environment. Following the same logic, the study (Jastrzębska et al., 2016a) examined $\zeta$ of the developed $\mathrm{GO} / \mathrm{Al}_{2} \mathrm{O}_{3}$ (40 \%wt.) nanocomposite flakes. The reference material was $\mathrm{GO}$ flakes and pure $\mathrm{Al}_{2} \mathrm{O}_{3}$ nanoparticles (not attached to RGO surface). The study was performed in a wide $\mathrm{pH}$ range in distilled water, electrolyte solution $(\mathrm{NaCl})$ and drinking water environment. Specific attention was paid to the analysis of the shape of $\zeta$ curves. Obtained results have shown a strong dependence of $\zeta$ value on the $\mathrm{pH}$ level and the chemical composition of water. These were, in turn, closely linked to changes in the chemical composition of materials' surface (Mikolajczyk et al., 2015). The interesting observation is the mitigating effect of the RGO 


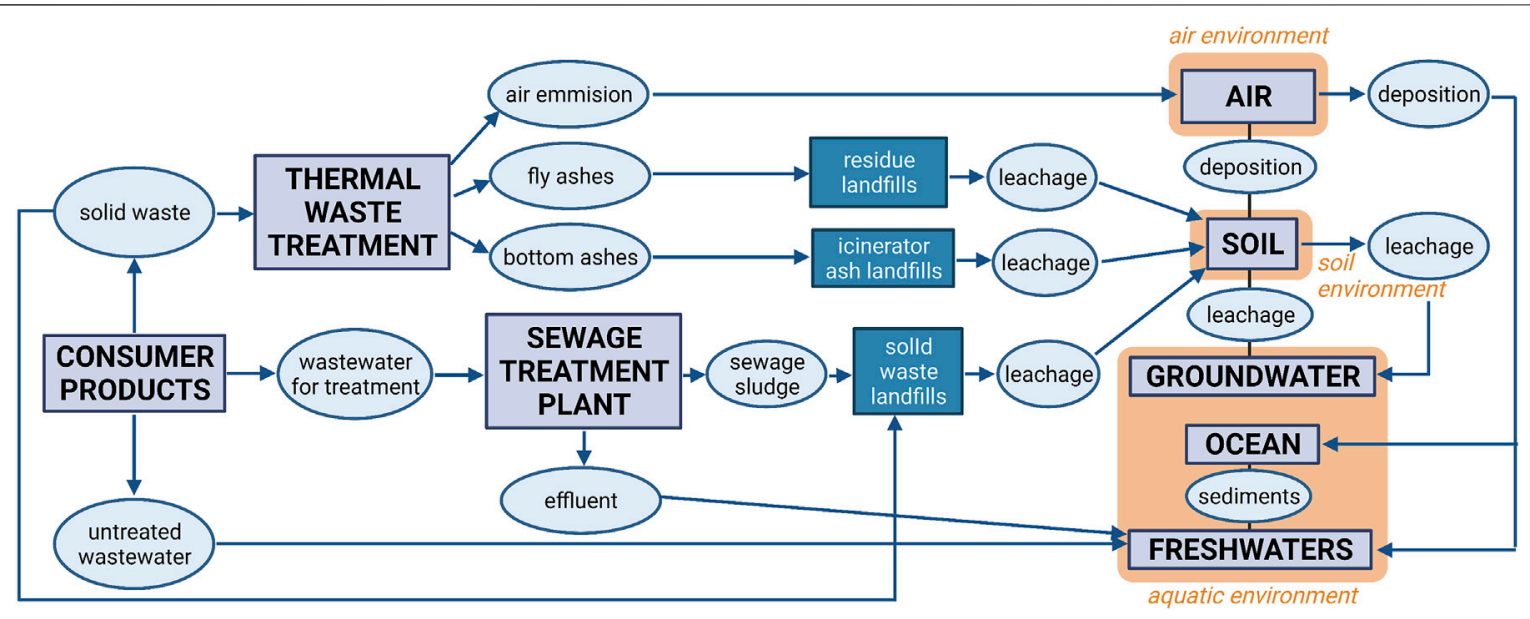

FIGURE 7 | Schematic of potential transfer pathways of the $\mathrm{RGO} / \mathrm{Al}_{2} \mathrm{O}_{3}$ nanocomposite in the natural environment as a result of their release from consumer products. Arrows correspond to the directions of transfer between the environmental biota (Reproduced with permission from (Jastrzębska and Olszyna, 2015) with minor changes)

core on measured $\zeta$ values for the developed $\mathrm{GO} / \mathrm{Al}_{2} \mathrm{O}_{3}$ nanocomposite system. Such changes can influence the environmental risk of GFMs.

In general, it is presumed that graphene does not possess a risk to the environment due to the small amounts produced and used as well as its uncomplicated structure, consisting only of carbon. It may, however, hold a threat, especially under certain conditions and in different environments (Arvidsson et al., 2018). Similar ecotoxicological effects can be assumed for other GFMs. However, some possible risks were noticed for GFMs in regard to their potential toxicity (Arvidsson et al., 2011; Jahnel, 2015). As there is a lack of studies considering $\mathrm{RGO} / \mathrm{Al}_{2} \mathrm{O}_{3}$ ecotoxicity, it is possible to consider $\mathrm{RGO}$ and $\mathrm{Al}_{2} \mathrm{O}_{3}$ components separately.

The ecotoxicity of GFMs has been presented in detail in a recent work (Jastrzębska and Olszyna, 2015). Other studies have shown that toxicity of $\mathrm{RGO} / \mathrm{NPs}$ synthesized via chemical reduction of NPs precursor depends on the surface properties of investigated organisms as well as chosen nanomaterials (Yin et al., 2020). The more hydrophobic and complex cells of $C$. reinhardtii were more sensitive than $S$. obliquus. Differences in the properties and chemistry of algal cells were related with increased toxicity, due to the more intense metal ion adsorption and interactions with NPs. What is more, induction of cellular oxidative stress, as well as membrane damage, occurred more often in case of RGO/NPs nanocomposites with more complex heterointerfaces. The synthesis method and properties of nanocomposites were only partially responsible for the toxicity, while the algal surface property was the main factor. Cellular metal accumulation and membrane damage due to the interactions with metallic NPs is disturbed, because of the presence of defensive mechanisms like metal pumping and secretion of exudates, as well as complex and heterogeneous composition of algae surface, which support binding of metals.

What is more, the hydrophobic surface of microalgae have a greater potential for biological interactions, which then disturb interconnections with hydrophobic nanomaterials. Further, in case of $C$. reinhardtii, monocarboxylic acids and amide groups, as well as polypeptides in outer surface of cell wall, which play a dominant role during the process of metal ion binding were observed. The short-term exposition of an ocular region in mice to RGO (synthesized via a hydrazine reduction) showed a much lower risk than in case of GO (obtained according to Hummers' method). A short-term exposure to GO caused apoptosis, necrosis, cell cycle alteration, and eyeball cell death (An et al., 2018). Contrary, both commercially available GO and chemically reduced RGO were not highly toxic to mussel hemocytes (Katsumiti et al., 2017). These GFMs can be, however, internalized into the cells, therefore increasing ROS formation, mitochondrial and lysosomal dysfunction, and cell death. It was concluded, that toxicity of GFMs may be also influenced by physicochemical properties (e.g., lateral dimensions), as well as increased stability, corresponding to higher availability and bioaccumulation inside the cells. The toxicity of different concentrations of GFMs to zebrafish embryos was investigated at the early stage of fish development (Liu et al., 2014). In case of RGO, synthesized by using a hydrazine GO reduction process, mortality, as well as significant development abnormalities (e.g., tail detachment, somite formation), was not detected. However, it was found that RGO affects significantly the hatching rate. The larvae length has been also affected to some extent, which can be related to the interference with hatching enzyme and hypoxia in zebrafish, due to the oxygen exchange disturbance.

Recent work (Załęska-Radziwiłł et al., 2020) considered the effect of aluminum oxide nanoparticles on aquatic organisms. It was revealed that long-term exposure (28 days) of microcosm caused the reduction of biodiversity of microbenthic and plankton organisms, with increased activity of antioxidative enzymes of benthos. It was also observed that nanoparticles tended to accumulate on the surface of Daphnia magna and in its mitochondria. This was not, however, the case for the bulk counterparts of nanoparticles. The toxicity of nano and bulk 


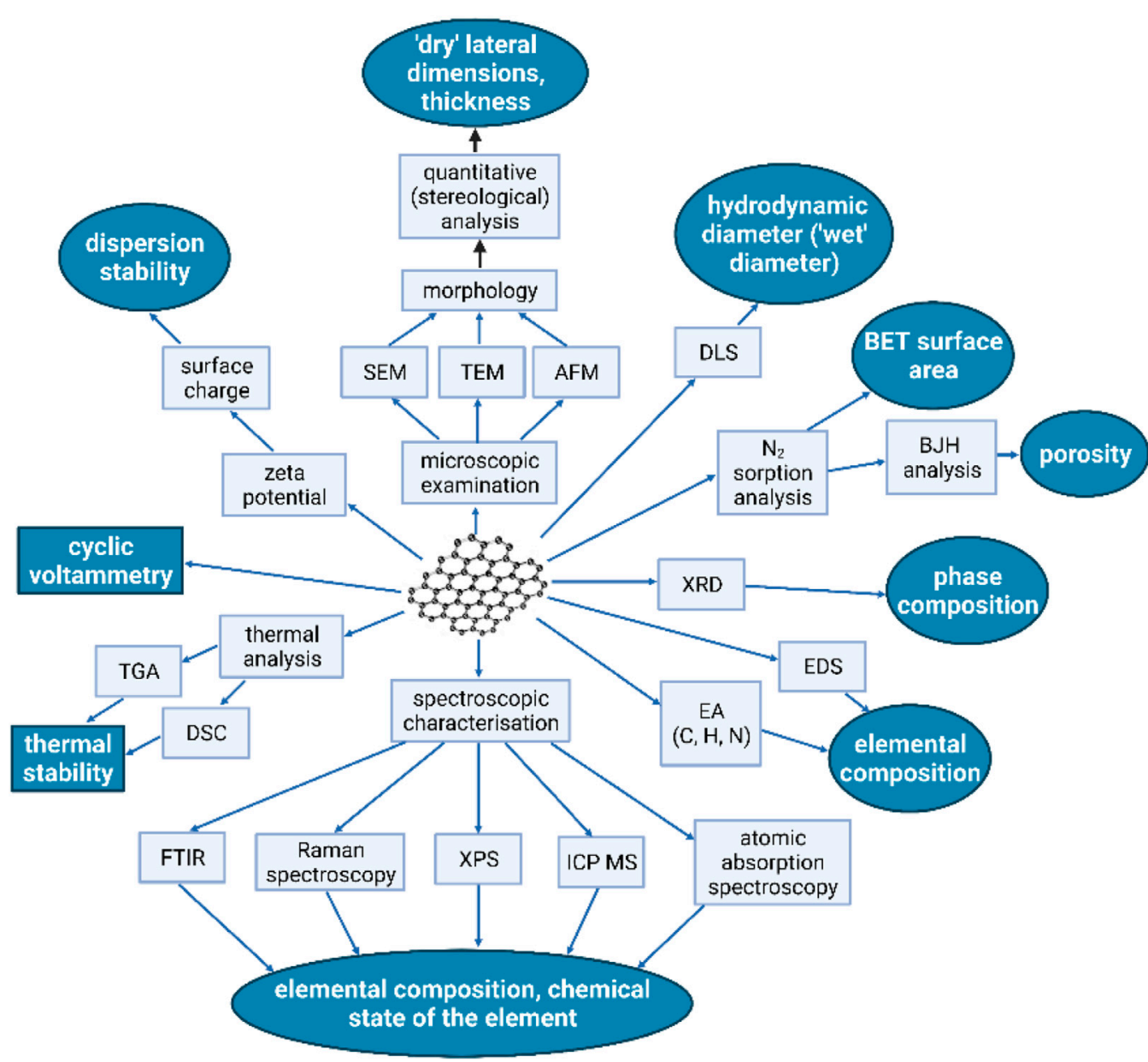

FIGURE 8 | Most important methods and research techniques applied in the characterization of graphene-family nanomaterials (GMFs). Fields marked in grey color represent GFMs parameters directly linked to their bioactive properties. For simplification, the following abbreviations were used: TEM, transmission electron microscopy; SEM, scanning electron microscopy; AFM, atomic force microscopy; DLS, dynamic light scattering; FT-IR, Fourier-transform infrared spectroscopy; XPS, X-ray photoelectron spectroscopy; XRD, X-ray diffraction; BET, Brunauer-Emmett-Teller; BJH, Barrett Joyner, Halenda; EDS, Energy-dispersive X-ray spectroscopy; TGA, Thermogravimetric analysis; DSC, differential scanning calorimetry; ICP-MS, inductively coupled plasma mass spectrometry (Reproduced with permission from (Jastrzębska and Olszyna, 2015) with minor changes).

$\mathrm{Al}_{2} \mathrm{O}_{3}$ towards Caenorhabditis elegans was compared in work (Wang et al., 2009a). The authors observed significant differences in toxicity of nano, micro and macroparticles, as shown by the lethality of the investigated worms, the number of eggs inside the body, and offspring per nematode.

The abovementioned results are of particular importance because they suggest that if the RGO surface is covered by $\mathrm{Al}_{2} \mathrm{O}_{3}$ NPs, the lateral size of the final nanocomposite is in micro-scale, rather than in nano-scale. Consequently, the potential toxicity of $\mathrm{RGO} / \mathrm{Al}_{2} \mathrm{O}_{3}$ should be diminished due to changes in the material's dimension. Yet, the potential nanotoxicity of free $\mathrm{Al}_{2} \mathrm{O}_{3}$ NPs is still a matter of concern. For instance, the growth of microalgae Isochrysis galbana was significantly inhibited in the presence of nano- $\mathrm{Al}_{2} \mathrm{O}_{3}$ at concentrations over $10 \mathrm{mg} \mathrm{L}^{-1}$ (Hu et al., 2018). It was found that $\mathrm{Al}_{2} \mathrm{O}_{3}$ NPs were able to penetrate the cell membrane and aggregate inside within it. This presumably caused the inhibition of microalgae growth, and interestingly, enhancement of cellular fluorescence emission (Hu et al., 2018). What is more, the presence of $\mathrm{Al}_{2} \mathrm{O}_{3} \mathrm{NPs}$ enhanced the toxic effects of $\mathrm{Pb}$ ions, manifested with increasing bio-uptake of $\mathrm{Pb}$. In this regard, the possible coexistence of nanomaterials and ions should be always taken into consideration in ecotoxicity analysis, since the synergistic effects may occur. On the other hand, the synergic toxicity of $\mathrm{Al}_{2} \mathrm{O}_{3}$ NPs and $\mathrm{Cr}(\mathrm{VI})$ ions was not observed in other works (Dalai et al., 2014), since the presence of nanoparticles did not change the bioavailability and uptake of $\mathrm{Cr}$. The solo $\mathrm{Al}_{2} \mathrm{O}_{3} \mathrm{NPs}$ were however ecotoxic towards freshwater microalgae, even at the lowest investigated concentration $\left(0.05 \mu \mathrm{g} \mathrm{ml}^{-1}\right)$. The most probable explanation of this issue is their physicochemical properties such as surface area, particle size. This is valid not only in case of GFMs but also for all types of nanomaterials. Their chemical state may change and they can transform while entering different biota, for instance, water or soil environment 

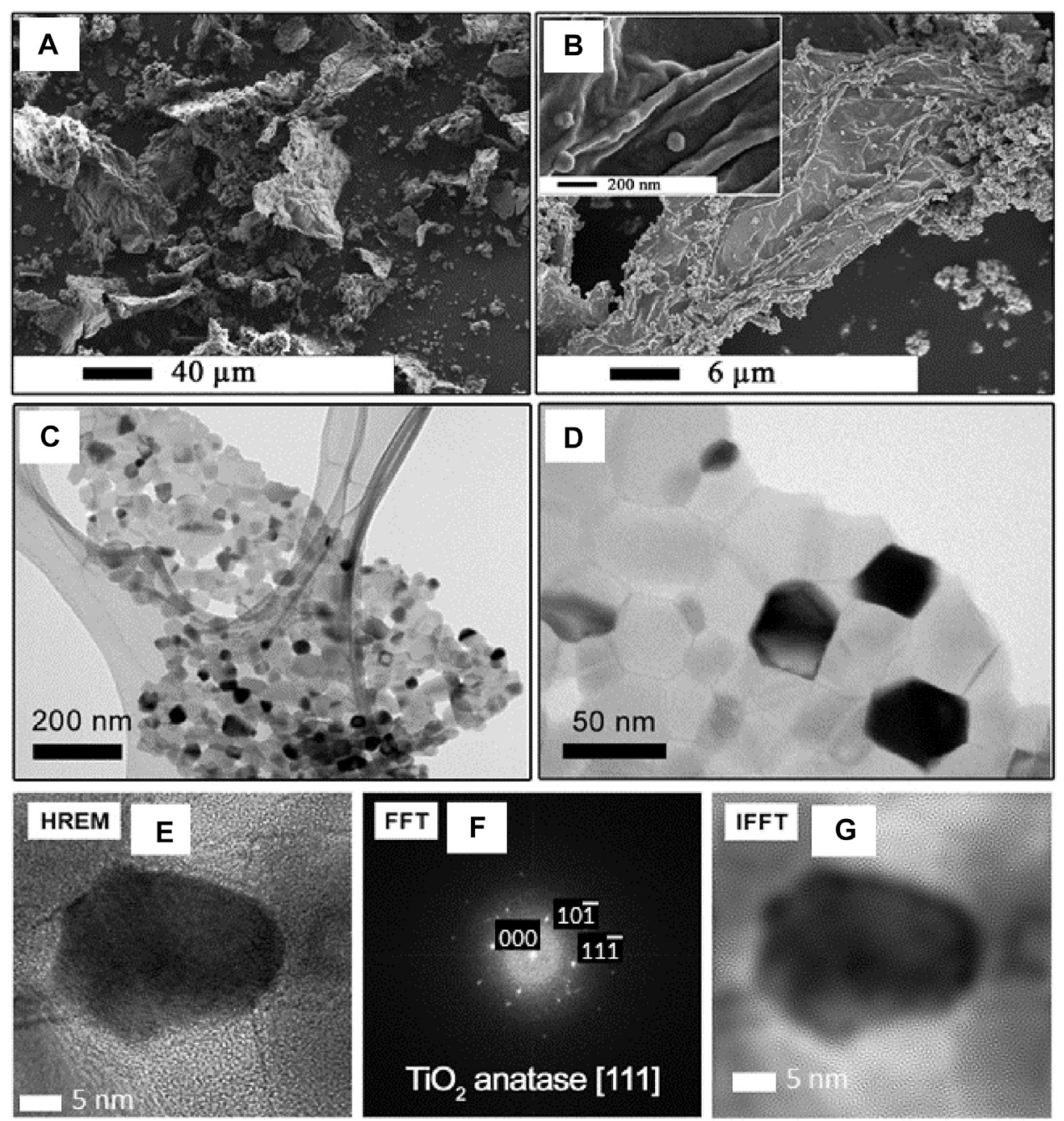

FIGURE 9| The morphology (A,B) and structure (C-F) of the $\mathrm{RGO} / \mathrm{TiO}_{2}(40$ wt\%) nanocomposite obtained using the simplified sol-gel method analysed with SEM and HREM analysis. The structure of $\mathrm{TiO}_{2} \mathrm{NPs}$ was analyzed using electron diffraction (F) and corresponding IFFT imaging (Reproduced with permission from (Jastrzebska et al., 2016) with minor changes).

and therefore, researching the close-to-real conditions may be the key to understanding their ecotoxicity (Peralta-Videa et al., 2011).

\section{ON THE RGO/TIO ${ }_{2}$ NANOCOMPOSITE SYSTEM}

\section{Synthesis Approaches}

The $\mathrm{RGO} / \mathrm{TiO}_{2}$ nanocomposites have recently seen an intensive development. It primarily aimed at obtaining photocatalytic systems that could utilize the unique electronic properties of graphene (Liang et al., 2010; Peter et al., 2015). Graphene/ $\mathrm{TiO}_{2}$ nanocomposites have been obtained using various techniques such as atomic layer deposition (Zhang et al., 2015), liquid phase deposition (Zhang et al., 2011b) as well as a hydrothermal method (Chang et al., 2012), hydrazine reduction, UV-assisted photoreduction, or sol-gel method (Zhang et al., 2010; Guo et al.,
2011). Intensive exploration of these techniques has shown that the modification of the graphene surface with $\mathrm{TiO}_{2}$ nanoparticles poses many difficulties. For instance, a problem of unsatisfactory bonding between $\mathrm{TiO}_{2}$ and graphene surface as well as the problem of $\mathrm{TiO}_{2}$ agglomeration was formulated (Zhang et al., 2010; Guo et al., 2011). Other works identified agglomeration of graphene flakes as a consequence of surface modification (Chang et al., 2012), lack of homogenous covering of the RGO surface by $\mathrm{TiO}_{2}$ nanoparticles (Liang et al., 2010) and lack of efficient interaction between GO surface groups and $\mathrm{TiO}_{2}$ nanoparticles (Williams et al., 2008; Fan et al., 2011). Therefore, the existing methods for surface modification of graphene with $\mathrm{TiO}_{2}$ are characterized by numerous disadvantages. Consequently, designing the graphene/ $\mathrm{TiO}_{2}$ nanocomposites in the form of core@shell structure in which individual (non-agglomerated) 2D RGO flakes (the core) are uniformly covered with $\mathrm{TiO}_{2}$ layer (the shell) is a challenge. 
Apart from many difficulties in the surface-modification of graphene flakes, the involvement of GO or RGO in synthesis is more promising for $\mathrm{RGO} / \mathrm{TiO}_{2}$ development. The newly developed simplified sol-gel method of synthesis of $\mathrm{RGO} / \mathrm{TiO}_{2}$ nanocomposite flakes allows for better surface coverage with $\mathrm{TiO}_{2}$ NPs and achieving a final product with a more uniform morphology (Jastrzebska et al., 2016). The method involves introducing organic titanium compound into GO flakes dispersion in an organic solvent. Then, the reaction sol is stirred to skip the sol/gel transition. The solvent is then removed and the obtained gel undergoes the air-induced thermal decomposition. The morphology of the $\mathrm{RGO} / \mathrm{TiO}_{2}$ is shown in Figure 9. The results of the high-resolution TEM and electronic diffraction (Figures 9E-G) confirms the presence of $\mathrm{TiO}_{2}$ NPs, mainly in the form of anatase.

\section{Biocidal Properties}

Importantly, the covalent functionalization of $\mathrm{GO}$ with $\mathrm{TiO}_{2}$ nanoparticles was confirmed also in this case and an in situ reduction of GO to RGO (Jastrzebska et al., 2016). A quantitative XPS analysis of changes in chemical composition of the GO surface has shown that the oxygen (in a form of -OH species) was almost completely transferred from the surface of GO to the structure of the titanium tetraisopropoxide (a $\mathrm{TiO}_{2}$ precursor). Contrary, the $\mathrm{O}=\mathrm{C}-\mathrm{OH}$ groups were not completely removed from the GO surface. The follow-up study (Jastrzebska et al., $2017 \mathrm{~d}$ ) analyzed the bioactive properties of $\mathrm{RGO} / \mathrm{TiO}_{2}$ nanocomposites. It was shown that $\mathrm{RGO} / \mathrm{TiO}_{2}$ stimulated the growth of S. aureus, E. coli, and Sarcina bacteria. Also, no bioactivity was observed in the case of the Bacillus sp. strain. Therefore, while the prepared nanomaterial exhibited no biocidal properties, interesting electrostatic properties were noticed in the water environment (Jastrzebska et al., 2016) that were very similar to $\mathrm{RGO} / \mathrm{Al}_{2} \mathrm{O}_{3}$ nanocomposites (Jastrzębska et al., 2016a). Development of the core@shell structure has modified the material's electrostatic properties, which was different from both pure GO and pure $\mathrm{TiO}_{2}$ NPs.

\section{Preparation of Photocatalytic Materials}

Recent work introduced the cost-effective and easy method for obtaining good quality $\mathrm{RGO} / \mathrm{TiO}_{2}$ thin films on fluorine-doped tin oxide (FTO) using a spray pyrolysis technique (SPT) (Alshammari et al., 2020). The homogeneous mixture of $\mathrm{TiO}_{2}$ nanopowder and GO dispersion was sprayed onto the FTO glass substrates, which were cleaned before the SPT. After spraying, the oxygen atoms were evaporated and removed from the surface due to the thermal decomposition and annealing process. Contrary, $\mathrm{RGO} / \mathrm{TiO}_{2}$ nano-flowers were synthesized using a facile, fluorinefree and non-toxic one-pot solvothermal technique (Pugazhenthiran et al., 2020). For this purpose, a dispersion of GO was subjected to ultrasonic treatment and stirring. Subsequently, the $\mathrm{TiO}_{2}$ NPs were added into homogeneous suspension and stirred once again. After that, the mixture was autoclaved, centrifuged, washed, and vacuum-annealed. Authors summarized that $\mathrm{RGO} / \mathrm{TiO}_{2}$ nanocomposite with highly exposed $\{001\}$ facets was characterized with good crystallization, high dye loading, improved charge transport and enhanced light scattering. The photovoltaic performance was significantly improved as well. The extraordinary photocatalytic dye degradation was shown by $\mathrm{RGO} / \mathrm{TiO}_{2}$ nanocomposite obtained via simple in-situ microwave synthesis (Kumar et al., 2015). In this method, GO was synthesized with Hummer's method and $\mathrm{TiO}_{2}$ nanocrystals were homogenized separately in ethanol using ultrasounds. The components were then mixed and stirred. After that, the mixture was exposed to microwave irradiation. Finally, the solvent was evaporated and then, the final product was washed with deionized water and dried. As in the previous cases, the presence of $\mathrm{TiO}_{2}$ NPs on RGO surface prevented restacking of RGO layers. Authors also speculated about the role of RGO in the photocatalytic activity of the obtained nanocomposite. They explained that RGO accepts electrons due to its nature, and after being negatively charged, it produces oxygen radicals. Further, because of the reaction with hydroxyl ions, the hydroxyl radicals are being produced. These radicals can degrade organic matter, as they possess large energetic states.

Other techniques for the preparation of $\mathrm{RGO} / \mathrm{TiO}_{2}$ nanocomposites with homogeneous morphology include the assistance of poly(methyl methacrylate) (PMMA) template using electrostatic assembly (Liu et al., 2018). In this method, PMMA template is redispersed in aqueous solutions and positively charged. Next, carboxylic GO is added dropwise, while the whole mixture is stirred. The next step involves a dropwise introduction of titanium precursor (i.e., tetrabutyl orthotitanate) and stirring. After the process, a nanocomposite is collected, dried in a vacuum and calcined to remove PMMA template. Using this approach, the $\mathrm{RGO} / \mathrm{TiO}_{2}$ is not agglomerated due to the application of a template. Such powdered $\mathrm{RGO} / \mathrm{TiO}_{2}$ structure was characterized by the presence of multi-level hierarchical pores and therefore, high specific surface area and large pore volume. It could be beneficial not only in case of biological activity but also hydrogen storage, as hierarchically porous structures allow the rapid diffusion of gases. A similar $\mathrm{RGO} / \mathrm{TiO}_{2}$ nanocomposite structure was obtained in a work (Olowoyo et al., 2019) using the combined sonothermalhydrothermal method. It is noted, however, that the procedure was highly complicated. The GO was prepared with modified Hummer's method and reduced to RGO hydrazine monohydrate in a toluene-based environment. In the next step, RGO was redispersed in water/ethanol solution and homogenized with ultrasounds. After that, few drops of $\mathrm{HNO}_{3}$ were added and the mixture was sonicated further, after which it was hydrothermally treated in an autoclave. Next, such obtained product was centrifuged, air-dried, and calcinated. Such composites showed good photocatalytic properties. As authors concluded, it's really important to find an optimal proportion of $\mathrm{TiO}_{2}$ and RGO to improve the photocatalytic properties of the final product. What is more, they observed that RGO is acting as a sensitizer for $\mathrm{TiO}_{2}$, which by itself shows little activity under visible light.

Photocatalytic activity of $\mathrm{RGO} / \mathrm{TiO}_{2}$ nanocomposites has been confirmed in many other studies. In recent work (Guan et al., 2021), the enhanced photocatalytic activity and stability of $\mathrm{TiO}_{2} /$ graphene oxide composite were obtained for coatings fabricated 
via electrophoretic deposition (EPD). Such composites were able to effectively enhance the photocatalytic activity under visible light, which was associated with forming of $\mathrm{TiO}_{2}$ coatings on the surface of GO. What is more, the combination of $\mathrm{TiO}_{2}$ and $\mathrm{GO}$ was stable, even after ultrasonic cleaning. As shown in (Jin et al., 2021), the photocatalytic activity of $\mathrm{TiO}_{2}$ combined with graphene 3D framework may be utilized for efficient adsorption-photocatalytic removal of micro-organic contaminants from water. The synthesis involved rapid freezing-drying followed by high-temperature hydrogen reduction. The $3 \mathrm{D} \quad \mathrm{RGO} / \mathrm{TiO}_{2}$ nanocomposite showed enhanced adsorption-photocatalytic activity for the removal of trace ethenzamide under both UV and vacuum ultraviolet (VUV) irradiation. As authors suggested, the creation of the 3D frame accelerated the transfer of photogenerated electrons, as well as diffusion of micro-organic contaminants. In a study (Yang et al., 2021) it has been shown, that photocatalytic activity of $\mathrm{TiO}_{2} /$ graphene composite can be also enhanced due to the assembly technique. Authors obtained $\mathrm{TiO}_{2}$ core@shell composites covered by graphene sheets via a stepwise process. For this purpose, templates were subsequently loaded and heat-treated under an inert atmosphere. Such coating strategy improved the contact area between $\mathrm{TiO}_{2}$ and graphene. These nanocomposites were able to separate more carriers generated in the photodegradation process (on both sides of core@shell) and reduce $\mathrm{CO}_{2}$ into $\mathrm{CO}$ more efficiently. In other work (Tismanar et al., 2021), authors applied the spray pyrolysis deposition (SPD) technique and sol-gel spraying to obtain photoactive $\mathrm{TiO}_{2}$ /graphene composite thin films. In this regard, factors that may influence the photocatalytic effect were investigated. It has been found that the obtained films were more dye-sensitive in VIS spectra, due to the presence of GO in the composite films. What is more, the efficiency of photodegradation of methylene blue and imidacloprid was influenced mostly by specific surface (roughness) and crystallinity. Furthermore, the washing out effect in an aqueous pollutant environment was not observed, which indicates their stability. Importantly, that such thin films could be also applied to self-cleaning surfaces (Dundar et al., 2020).

\section{ON THE RGO/METAL OXIDE-ME NANOCOMPOSITE SYSTEM}

\section{Preparation of Biocidal Hybrids}

The next important step in the development of RGO/metal oxide nanocomposites is the addition of bioactive NPs, which can be composed of various noble metals. The subject literature explores in the majority, the synthesis of graphene-based nanocomposites for use as biocides. The direct decoration method from nanoparticle suspension enabled the modification of graphene surface with nano-Pt, Pd (Xu et al., 2008), Au (Muszynski et al., 2008), Sn (Wang et al., 2009b), and Ag (Chook et al., 2012). Apart from these, only GO/Ag nanocomposite showed biocidal properties. More complicated systems in terms of use for filtration of drinking water include those containing metal oxides. The resulting structure is, obviously, more complex
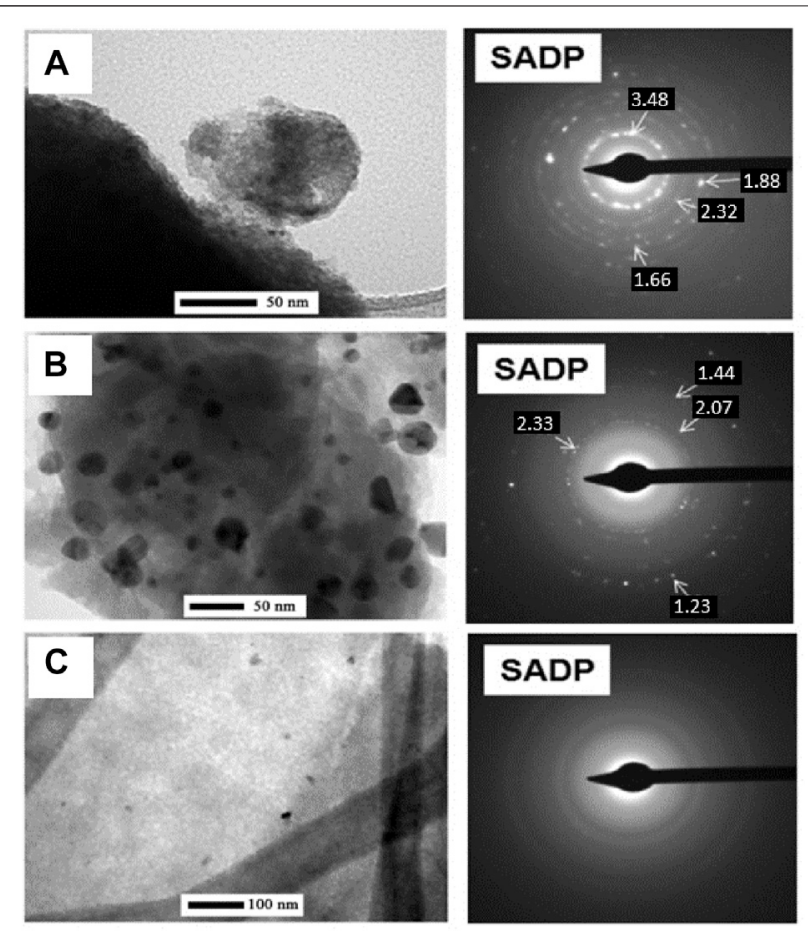

FIGURE 10 | Structural TEM analysis (including electron diffraction (SADP)) with identification of precious metals for nanocomposites such as $\mathrm{RGO} / \mathrm{TiO}_{2}$ (40 wt\%)-Ag (1 wt\%) (A), RGO/TiO 2 (40 wt\%)-Au (1 wt\%) (B), $\mathrm{RGO} / \mathrm{TiO}_{2}$ ( $40 \mathrm{wt} \%$ )-Pd (1 wt\%) (C) produced using the simplified solgel method (Reproduced with permission from (Jastrzebska et al., 2017d) with minor changes).

which causes an additional challenge in materials design and optimization. Research in this field was conducted for systems containing $\mathrm{TiO}_{2}$ and Ag NPs. In work (Liu et al., 2013), a GO/ $\mathrm{TiO}_{2}$-Ag nanocomposite demonstrated antimicrobial properties against $E$. coli bacteria. However, its synthesis consisted of mixing GO flakes with separately prepared $\mathrm{TiO}_{2}$ fibers and $\mathrm{Ag}$ precursor. As a result, Ag NPs were not covalently bonded to the surface of GO flakes.

Two years later, other work (Yang et al., 2015) presented the $\mathrm{TiO}_{2}(\mathrm{P} 25) / \mathrm{Ag}_{3} \mathrm{PO}_{4} / \mathrm{GO}$ composite using electrostatic interactions and the ion-exchange method. In this process, $\mathrm{Ag}_{3} \mathrm{PO}_{4}$ was also mixed with separately-prepared $\mathrm{TiO}_{2}$ NPs. The obtained composite efficiently deactivated E. coli, S. aureus, Salmonella typhi, Pseudomonas aeruginosa, Bacillus subtilis and Bacillus pumilus. In another work (Vasilaki et al., 2015), authors obtained the $\mathrm{RGO} / \mathrm{TiO}_{2}$ - $\mathrm{Ag}$ nanocomposite using a two-step strategy. In the first step, the photocatalytic nano- $\mathrm{TiO}_{2}$ (P25, Degussa) was modified by Ag NPs. Secondly, the GO flakes were modified by $\mathrm{TiO}_{2}$-Ag using the hydrothermal method. The authors declared the occurrence of reduction of GO to RGO, however, with no in-depth analysis of the reaction mechanisms. It was also noted that the $\mathrm{TiO}_{2}-\mathrm{Ag}$ NPs did not fully cover the surface of RGO. The abovementioned results show that the most preferred GFM in various synthesis processes is the GO, due to its high surface wettability and corresponding dispersibility. 

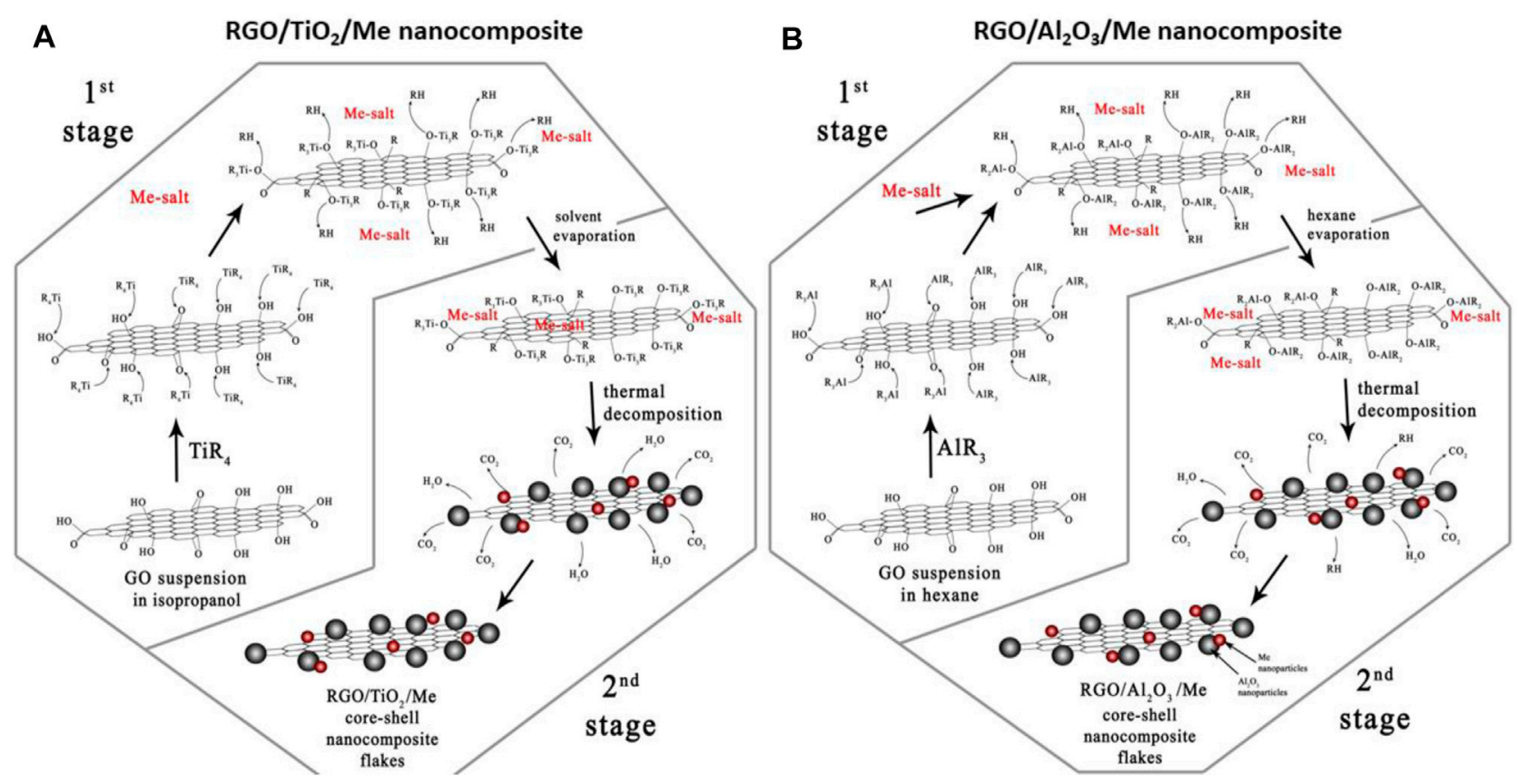

FIGURE 11 | Schematic representation of the mechanism of covalent modification of $\mathrm{GO}$ surface with $\mathrm{TiO}_{2}-\mathrm{Me} \mathrm{nanoparticles} \mathrm{toward} \mathrm{nanohybrid} \mathrm{RGO} / \mathrm{TiO}_{2}-\mathrm{Me}_{\mathbf{A}}$ ( $)$ and $\mathrm{RGO} / \mathrm{Al}_{2} \mathrm{O}_{3}-\mathrm{Me}$ (B) composite systems, using the simplified sol-gel method (Reproduced with permission (Jastrzebska et al., 2017d), (Jastrzębska et al., 2016b), respectively).

Therefore, the RGO/metal oxide-Me (where: $\mathrm{Me}=$ precious metal) nanohybrid system could be an interesting research topic for further studies.

The paper (Jastrzębska et al., 2017c) focused on the comparison of bioactive properties of RGO modified by selected NPs of metal oxides such as $\mathrm{Al}_{2} \mathrm{O}_{3}, \mathrm{TiO}_{2}, \mathrm{ZnO}_{2}, \mathrm{SiO}_{2}$ as well as silver $\mathrm{NPs}(\mathrm{Me}=\mathrm{Ag})$. The $\mathrm{RGO} / \mathrm{Al}_{2} \mathrm{O}_{3}-\mathrm{Ag}, \mathrm{RGO} / \mathrm{TiO}_{2^{-}}$ $\mathrm{Ag}, \mathrm{RGO} / \mathrm{SiO}_{2}-\mathrm{Ag}$ and $\mathrm{RGO} / \mathrm{ZnO}_{2}-\mathrm{Ag}$ nanocomposites were produced using the simplified sol-gel method. The smallest agglomeration was observed for $\mathrm{Al}_{2} \mathrm{O}_{3}-\mathrm{Ag}$ and $\mathrm{TiO}_{2}-\mathrm{Ag}$ NPs covering the RGO surface (Jastrzębska et al., 2017c). In this constellation of nano-compositions, the antibacterial effect was observed for the $\mathrm{RGO} / \mathrm{Al}_{2} \mathrm{O}_{3}-\mathrm{Ag}, \mathrm{RGO} / \mathrm{TiO}_{2}-\mathrm{Ag}$ and $\mathrm{RGO} / \mathrm{SiO}_{2^{-}}$ $\mathrm{Ag}$ nanocomposites. The strongest biocidal effect against $E$. coli, $S$. aureus and Bacillus sp. was observed in the case of the RGO/ $\mathrm{SiO}_{2}$-Ag nanocomposite. The $\mathrm{RGO} / \mathrm{TiO}_{2}-\mathrm{Ag}$ was most efficient against Sarcina sp.

In a follow-up study (Jastrzebska et al., 2017d), the works were continued on the $\mathrm{RGO} / \mathrm{TiO}_{2}-\mathrm{Me}$ system, where Me was labeled as NPs of precious metals $(\mathrm{Me}=\mathrm{Ag}, \mathrm{Au}, \mathrm{Pd})$. A method of obtaining nanohybrid graphene sorbents from the $\mathrm{RGO} / \mathrm{TiO}_{2}-\mathrm{Me}$ system consists of mixing organometallic titanium compound, a precious metal compound, or a mixture of such compounds is added to the graphene flakes or graphene oxide dispersed in an organic solvent. Then, the material is stirred in the presence of dry or wet air, the solvent is removed and the residues after drying undergo air-induced thermal decomposition (Jastrzebska et al., 2017e). Herein, transmission electron microscopy (TEM, see Figure 10) revealed the presence of Ag NPs (Figure 10A) and $\mathrm{Au}$ (Figure 10B) in $\mathrm{TiO}_{2}$ matrix.
The XPS analysis was used for examination of the mechanism of the process of covalent modification of GO surface with $\mathrm{TiO}_{2}$ Me NPs, for obtaining hybrid nanocomposite $\mathrm{RGO} / \mathrm{TiO}_{2}$ (40 wt $\%)-\mathrm{Me}(1 \mathrm{wt} \%)$ (Jastrzebska et al., 2017c). The mechanism was schematically presented in Figure 11A. The chemical reactions are taking place mainly between $\mathrm{C}-\mathrm{OH}$ groups and titanium tetraisopropoxide and involve the co-deposition of silver in the form of silver salts. As a result, -OH groups form the GO surface react with titanium tetraisopropoxide, while no reduction of $\mathrm{C}=\mathrm{O}$ and $\mathrm{O}=\mathrm{C}-\mathrm{OH}$ residual groups. Then, as a result of thermal decomposition, the removal of part of the organic precursor occurs. Consequently, $\mathrm{TiO}_{2} \mathrm{NPs}$ and precious metal NPs are simultaneously formed on RGO surface.

Based on the results obtained in (Jastrzebska et al., 2016) and (Jastrzebska et al., 2017e), it was assumed that $\mathrm{RGO} / \mathrm{Al}_{2} \mathrm{O}_{3}$ system modified with precious metal NPs is the most promising for further studies. The work (Jastrzębska et al., 2016b) presents a method of $\mathrm{RGO} / \mathrm{Al}_{2} \mathrm{O}_{3}-\mathrm{Me}$ nanocomposite (where $\mathrm{Me}=\mathrm{Ag}, \mathrm{Au}$, $\mathrm{Pd}$ ) synthesis. Also in this case, the mechanism of GO reduction to RGO was proposed (see Figure 11B). It is noted that a reduction of XPS signals corresponding to $\mathrm{C}-\mathrm{OH}$ species was observed as well as in previous approaches. Further, the precious metals (Ag, $\mathrm{Au}, \mathrm{Pd}$ ) NPs were co-deposited with $\mathrm{Al}_{2} \mathrm{O}_{3}$ on the surface of RGO.

Other works also involved $\mathrm{Cu}$ as the modifying NPs (Sadoun and Fathy, 2019). The solid $\mathrm{RGO} / \mathrm{Al}_{2} \mathrm{O}_{3}-\mathrm{Cu}$ nanocomposite was manufactured using a powder metallurgy technique. The RGO, $\mathrm{Al}_{2} \mathrm{O}_{3}$ and $\mathrm{Cu}$ were mixed in ethanol in a planetary ball mill until full homogeneity was achieved and then consolidated. The obtained samples revealed improvement of hardness and wear 


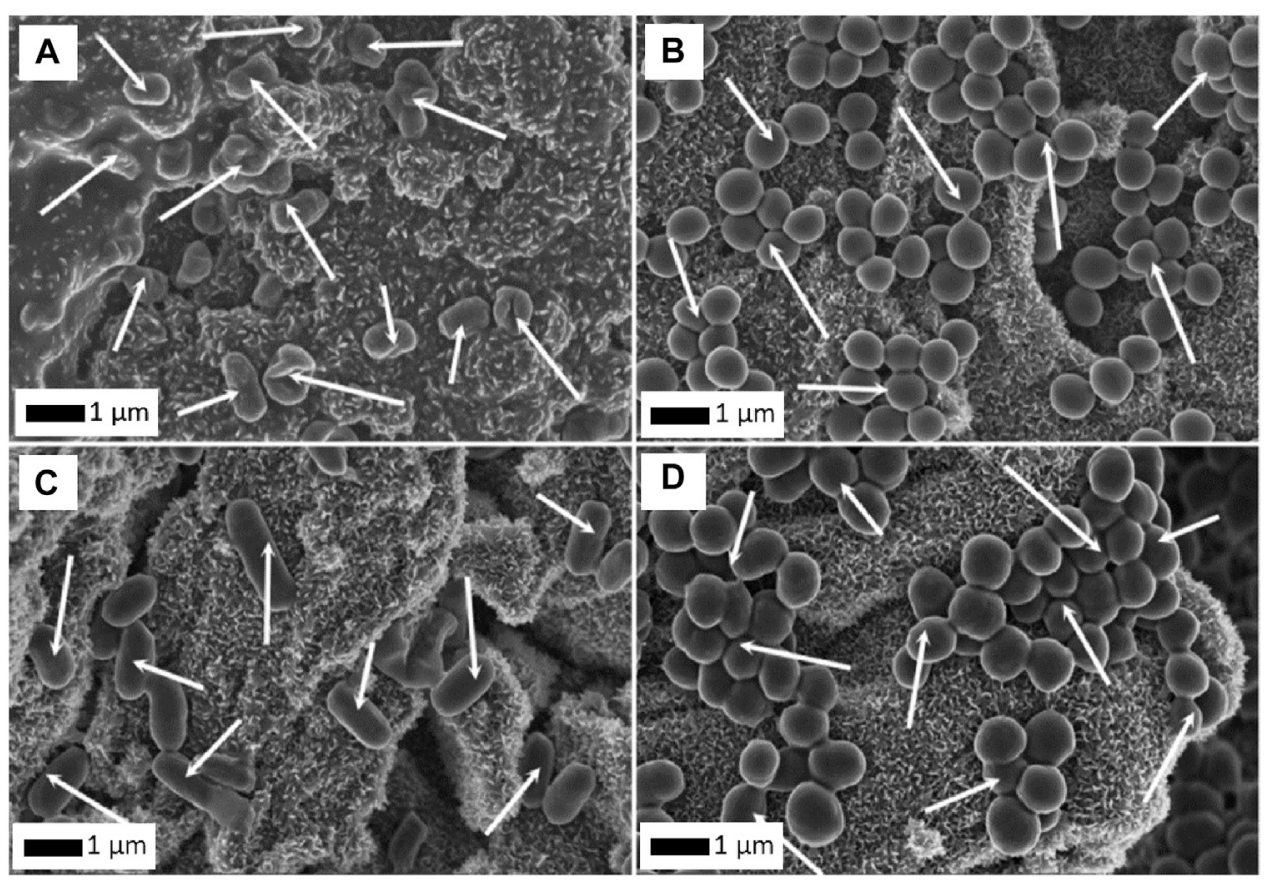

FIGURE 12 | Biosorption of E. coli (A), S. aureus (B), Bacillus sp. (C) and Sarcina (D) cells on the surface of $\mathrm{RGO} / \mathrm{Al}_{2} \mathrm{O}_{3}$-Au nanocomposite. Arrows point to bacterial cells (Reproduced with permission from (Jastrzębska et al., 2017e) with minor changes).

resistance while increasing the RGO content. What is more, authors also showed a high homogeneity of the obtained nanocomposite, as well as reinforcing grain boundaries due to the presence of RGO. The $\mathrm{Al}_{2} \mathrm{O}_{3}$ coating also improved the morphology, as it allowed to preserve structural voids as well as obtaining the almost spherical shape of nanoparticles. Another important aspect of research is the adhesion between alumina and copper nanoparticles which is much better in comparison to $\mathrm{Cu}$ and RGO. Thus, $\mathrm{Al}_{2} \mathrm{O}_{3}$ acts as a bridge and consolidates these into one solid nanocomposite structure, and therefore improves load and transfer capability between $\mathrm{Cu}$ and RGO.

\section{Bioactivity and Biosorption Properties}

$\mathrm{The} \mathrm{RGO} / \mathrm{TiO}_{2}(40 \mathrm{wt} \%)-\mathrm{Me}(1 \mathrm{wt} \%)$ nanocomposites were also a subject of bioactivity analysis which demonstrated that the RGO/ $\mathrm{TiO}_{2}-\mathrm{Ag}$ nanocomposite showed a growth stimulation of $S$. aureus, Sarcina and E. coli strains, while the $\mathrm{RGO} / \mathrm{TiO}_{2}-\mathrm{Au}$ caused the increased growth of $S$. aureus and Sarcina. In case of other samples, no bioactivity was observed. The obtained materials possessed properties stimulating bacterial growth, which showed their potential usefulness as a bacteria culture medium. Results obtained in (Jastrzębska et al., 2017c) confirmed the applicability of the $\mathrm{RGO} / \mathrm{Al}_{2} \mathrm{O}_{3}-\mathrm{Ag}$ system for biocidal applications because RGO modified with metal oxides other than $\mathrm{Al}_{2} \mathrm{O}_{3}$ exhibited high agglomeration and/or low biocidal efficiency.

Further analysis of $\mathrm{RGO} / \mathrm{Al}_{2} \mathrm{O}_{3}(40 \mathrm{wt} \%)-\mathrm{Me}(1 \mathrm{wt} \%)$ nanocomposites demonstrated their antibacterial activity, but only when Ag nanoparticles were present in the structure. The antibacterial effect was available against the $S$. aureus strain. The presence of other precious metals (especially $\mathrm{Pd}$ ) caused lower viability for certain bacterial strains (Jastrzębska et al., 2016b). Therefore, the presence of $\mathrm{Ag}$ in the material is essential to obtain biocidal properties in the $\mathrm{RGO} / \mathrm{Al}_{2} \mathrm{O}_{3}$ nanocomposites.

The next stage of research involved studies on water filtration systems (Jastrzębska et al., 2017e). The works involved RGO/ $\mathrm{Al}_{2} \mathrm{O}_{3}$-Me nanocomposites against E. coli, S. aureus, Bacillus sp., and Sarcina $s p$ bacteria. The system with the addition of Au NPs showed the best bacteria biosorption properties (Figure 12). In our recent work (Jakubczak et al., 2021), we evaluated $\mathrm{GO} / \mathrm{Al}_{2} \mathrm{O}_{3^{-}}$ $\mathrm{Ag}$ hybrid nanocomposite for tap water filtration efficiency. Our system showed high efficiency against both model and waterborne strains microorganisms, stability, reusability as well as self-sterilization ability. Within short periods of contact time, the nanocomposite was able to eliminate up to $100 \%$ of the filtered bacteria cells.

The quantitative analysis of morphology for bacterial cells adsorbed on the surface of the $\mathrm{RGO} / \mathrm{Al}_{2} \mathrm{O}_{3}$ - Me nanocomposites was carried out as part of the recent work (Jastrzębska et al., 2017e). The quantitative analysis was carried out for the S. aureus, Bacillus sp. and Sarcina strains using the method applied in the microstructural analysis of nanomaterials-the stereological analysis described in (Jastrzębska et al., 2016b) and (Jastrzebska et al., 2016). The stereological approach was applied for the first time to carry out a quantitative analysis of the morphology of bacterial cells (Jastrzębska et al., 2017e). The $E(p)$ parameter was used to describe the true shape of bacterial cells. It was chosen from a broad range of various stereological parameters employed in graphical analysis of changes in the morphology of individual bacteria cells, resulting from the 


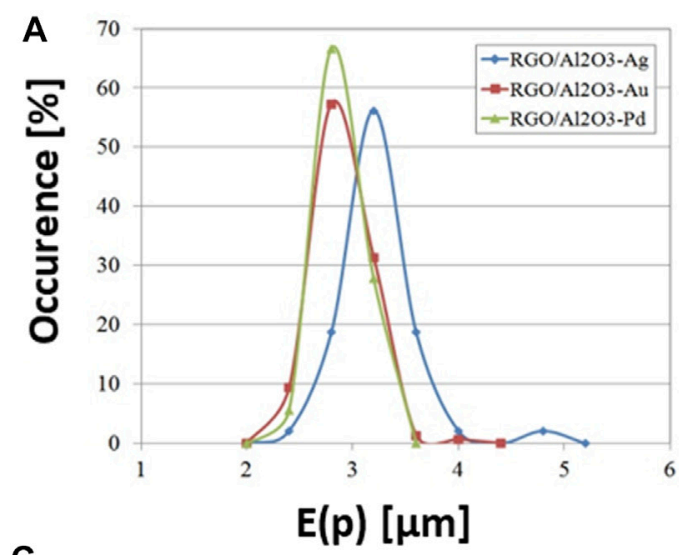

C
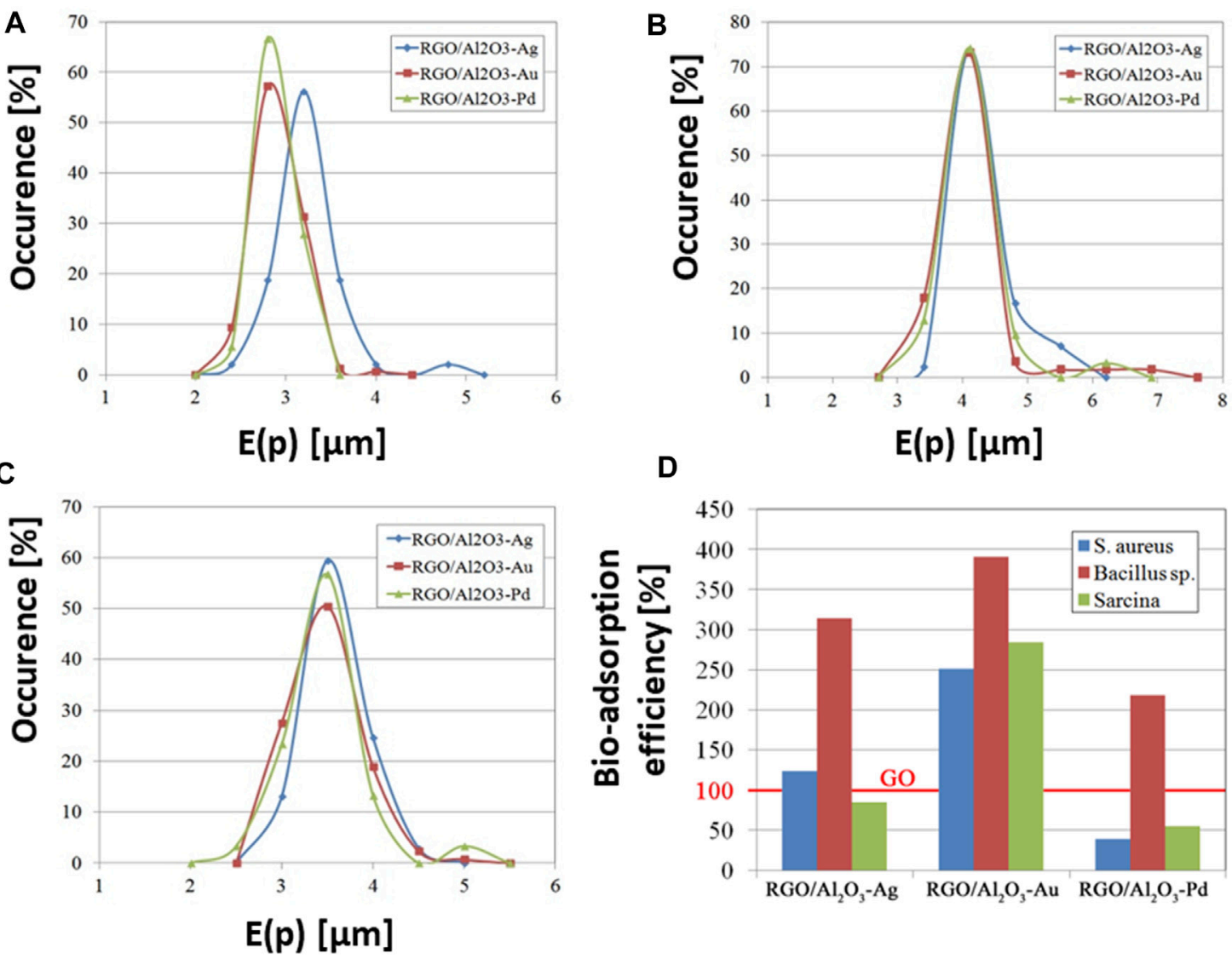

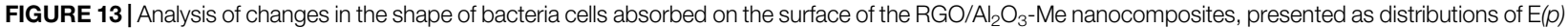
values for S. aureus (A), Bacillus sp. (B), and Sarcina (C) strains (Reproduced with permission from (Jastrzębska et al., 2017e)). Bacteria adsorption efficiency tested for $\mathrm{RGO} / \mathrm{Al}_{2} \mathrm{O}_{3}-\mathrm{Me}$ nanocomposites in comparison to the reference GO flakes (D), for which the benchmark of the $100 \%$ efficiency is assumed (Reproduced with permission from (Jastrzębska et al., 2017e) with minor changes).

interaction with the $\mathrm{RGO} / \mathrm{Al}_{2} \mathrm{O}_{3}-\mathrm{Me}$ nanocomposite surface. The $\mathrm{E}(p)$ distributions designated for the $S$. aureus cells (Figure 13A) adsorbed on the surface of the $\mathrm{RGO} / \mathrm{Al}_{2} \mathrm{O}_{3}$ - $\mathrm{Au}$ and the $\mathrm{RGO} /$ $\mathrm{Al}_{2} \mathrm{O}_{3}$ - $\mathrm{Pd}$ were comparable, which suggests a lack of changes in cell morphology. The analysis of cells after adsorption on the surface of the $\mathrm{RGO} / \mathrm{Al}_{2} \mathrm{O}_{3}$ - $\mathrm{Ag}$ nanocomposite showed shifting of $\mathrm{E}(p)$ towards higher values. Such a result suggests an increase in cell shapes directly associated with morphological changes (more irregular surface of the cell wall or cells' inflation/shrinkage). The observed effect was linked to the presence of biocidal Ag NPs in the surface structure of the $\mathrm{RGO} / \mathrm{Al}_{2} \mathrm{O}_{3}-\mathrm{Ag}$ nanocomposite. Using the method of quantitative analysis of cell morphology, it was possible to detect even small changes in $\mathrm{E}(p)$ values for Bacillus sp. (Figure 13B) and Sarcina (Figure 13C) cells adsorbed on the surface of the $\mathrm{RGO} / \mathrm{Al}_{2} \mathrm{O}_{3}-\mathrm{Ag}$ (Jastrzębska et al., 2017e).

Another important approach is the analysis of biosorption efficiency for the $\mathrm{RGO} / \mathrm{Al}_{2} \mathrm{O}_{3}$-Me nanocomposites (Figure 13D). Such quantitative analysis is based on a determination of the number of bacteria adsorbed per unit of nanocomposite area. The reference material was GO flakes, for which the $100 \%$ adsorption efficiency was assumed as a benchmark (Xu et al., 2008). Obtained results indicate that the $\mathrm{RGO} / \mathrm{Al}_{2} \mathrm{O}_{3}-\mathrm{Au}$ nanocomposite showed the best bio-adsorption efficiency for S. aureus $\left(6.1\right.$ cells $\left./ 10 \mu \mathrm{m}^{2}\right)$, Bacillus sp. $\left(1.9\right.$ cells $\left./ 10 \mu \mathrm{m}^{2}\right)$, and Sarcina ( 13.1 cells $/ 10 \mu \mathrm{m}^{2}$ ), while the $\mathrm{RGO} / \mathrm{Al}_{2} \mathrm{O}_{3}-\mathrm{Ag}$ exhibited a medium level of biosorption efficiency. For the case of $\mathrm{RGO} /$ $\mathrm{Al}_{2} \mathrm{O}_{3}$-Pd nanocomposite, the lowest biosorption effect was observed.

\section{Preparation of Electroactive Hybrids}

In other work (Sangjan et al., 2019), $\mathrm{RGO} / \mathrm{TiO}_{2}-\mathrm{Ga}$ and $\mathrm{RGO} /$ $\mathrm{TiO}_{2}$-Gd nanocomposites were successfully obtained using a simple procedure. Starting reagents were stirred together and then separated via centrifugation. Next, samples were washed using deionized water and dried in the air. In further research, obtained materials were characterized and investigated in terms of photocatalytic dye degradation. It was found that the introduction of metals allows for more effective degradation of the blue dye. It is noted that after reaching a certain percent addition of both $\mathrm{Ga}$ and $\mathrm{Gd}$, there was no further improvement in efficiency because a key factor here is an optimization of metal content. As authors concluded, the addition of metal into RGO/ $\mathrm{TiO}_{2}$ photocatalyst increases sub energy band gap of $\mathrm{TiO}_{2}$ and decreases the photoresponse energy. However, at the high 
concentration, material agglomerates with $\mathrm{TiO}_{2}$. This reduces the number of active sites and decreases photoreaction efficiency. The enhanced photoelectrocatalytic activity of the $\mathrm{TiO}_{2}$ was also obtained in work (Dargahi et al., 2018). For that, authors doped Mo with titanium using the mechanical alloying technique, which was then hybridized with RGO. Mo-doped $\mathrm{TiO}_{2}$ and GO were mixed and homogenized using ultrasounds. Next, water was removed from the sample, replaced with absolute ethanol and once again sonicated. In the end, the suspension was exposed to UV light $(350 \mathrm{~nm})$ and dried afterward. The fabricated nanocomposite was characterized by a significant enhancement in the photogenerated current (7.8 times higher compared to the bare $\mathrm{TiO}_{2}$ ), which corresponded to the reduction of the bandgap energy of the $\mathrm{TiO}_{2}$, as well as the efficient separation and prolonged recombination time of the charge carriers.

As shown in another study (Ahmadi et al., 2018), the photoelectric properties can be improved by doping RGO/ $\mathrm{TiO}_{2}$ nanocomposite with $\mathrm{Ce}$, instead of Mo. Authors doped $\mathrm{TiO}_{2}$ with $\mathrm{Ce}$ using the sol-gel method, in which precursor reagents were mixed separately with absolute ethanol. Next, both suspensions were combined, stirred, and $\mathrm{pH}$ was adjusted to start sol-gel transformation. Thus obtained gel was then dried and calcinated, which ended the procedure. Further, $\mathrm{RGO} / \mathrm{TiO}_{2}-$ Ce nanocomposite was synthesized using the hydrothermal method (Ahmadi et al., 2018). Firstly, GO was dispersed in absolute ethanol and deionized water, after which the suspension was homogenized with ultrasounds. Next, Cedoped $\mathrm{TiO}_{2}$ NPs were added and the whole suspension was stirred until full homogenization. The last step involved placing the suspension into a teflon-sealed autoclave and heating, after which it was filtered and dried to obtain the final sample. As was shown, the $\mathrm{RGO} / \mathrm{TiO}_{2}-\mathrm{Ce}$ photoelectric properties were rather different in comparison to its bulk counterpart. Combining reduced graphene oxide, titania and Ce resulted in a shift of absorption spectra toward visible light, decrease in photoluminescence emission (70\% lower than reference $\mathrm{TiO}_{2}$ ), high electronic conductivity, reduction of the charge carrier recombination rate and increase of the electrical conductivity.

The influence of different geometries of Ag NPs in improving the photocatalytic efficiency of $\mathrm{RGO} / \mathrm{TiO}_{2}-\mathrm{Ag}$ nanocomposite was also investigated (Chen et al., 2020b). Authors applied Ag nanospheres, nanodecahedrons and nanoprisms, which have been prepared separately and then, incorporated during the nanocomposite synthesis. As synthesized Ag NPs dispersions were mixed with $\mathrm{TiO}_{2}$ and then, the RGO was added. The mixture was then stirred, homogenized, dried in an oven, and ball-milled until the homogenous powder was formed. Further analysis revealed that the introduction of all Ag nanostructures allowed for enhancing the absorbance of co-catalyst in both UV and visible light ranges. What is more, nanocomposite with $\mathrm{Ag}$ nanodecahedrons showed a broader absorption in the longwavelength region (in comparison with Ag nanospheres). This was explained by the presence of localized surface plasmon resonance effect for $\mathrm{Ag}$ nanodecahedrons. Due to the multiple-resonance property of $\mathrm{Ag}$ nanoprisms, the resulting
$\mathrm{RGO} / \mathrm{TiO}_{2}-\mathrm{Ag}$ nanocomposite was characterized by extinction enhancement that was stretched all over the visible light spectrum. The absorption was enhanced not only by the addition of $\mathrm{Ag}$ nanoparticles but also the introduction of RGO, which strongly affected the redshift in the absorption edge. The importance of not only improving materials properties but also synthesis using environmentally friendly techniques (green synthesis) was recognized in work (Zhang et al., 2017). Authors obtained $\mathrm{RGO} / \mathrm{TiO}_{2}-\mathrm{Pd}$ nanocomposite by a simple two-step process using hydrothermal synthesis and reduction. For that, the GO, synthesized with modified Hummers' method, was dispersed in deionized water and homogenized using ultrasounds. In the next step, titania precursor was added, and the mixture was stirred under ultrasounds, after which it was transferred into an autoclave. Thus obtained samples were washed with water and dried under vacuum. Such nanocomposites were then doped with Pd. After redispersing and ultrasound homogenization, the $\mathrm{Pd}$ precursor was added and the whole was mixed. Lastly, the $\mathrm{KBH}_{4}$ solution was added dropwise to reduce $\mathrm{Pd}^{2+}$ under constant stirring of the mixture. Noticed improvement of electrochemical performance was assigned to the synergic effect of $\mathrm{TiO}_{2}-\mathrm{Pd}$, which was supported by the large specific surface area and superior conductivity of RGO.

\section{CONCLUSION AND OUTLOOK}

The development of nanohybrid systems enriched with graphene family nanomaterials (GFMs) hold great promise for innovations in the area of bioactive materials as well as various water treatment technologies. The GFM/metal oxide-bioactive metal nanohybrids can be obtained using the covalent surface modification of GFMs with nanoparticles. To be useful in the filtration of drinking water and its decontamination, they should exhibit both biocidal and biosorption properties to bacterial cells and/or catalytical features. Recent developments in the field are, unfortunately, scarce. However, they allow for important assumptions on the expected properties. The modification of GFMs with nanoparticles needs a careful examination of material morphology, structure, and functional properties. In this regard, understanding the general surface activity, bioactivity and the associated sorption phenomena are of high interest. These are also a must to enabling moving forward with nanotechnology development and further upscaling. The most substantial steps in this area include designing the structure and chemical composition of hybrid systems, developing innovative methods for covalent modification, and optimization of synthesis parameters. In this regard, confirmation of the existence of covalent bonds between the surface of the GO and nanoparticles plays a vital role together with a comprehensive description of morphology, structure, and physicochemical properties of the obtained bioactive and biosorption nanocomposite systems.

Within the most recent research in the field of bioactive GFMbased hybrids, it was demonstrated that the developed $\mathrm{RGO} / \mathrm{Al}_{2} \mathrm{O}_{3}$ $\mathrm{Me}$ nanocomposites are characterized by the best biosorption 
properties for Bacillus sp. and E. coli cells, which confirmed their further applicability in the filtration of drinking water. The RGO/ $\mathrm{Al}_{2} \mathrm{O}_{3}-\mathrm{Ag}$ nanocomposite was recognized as the most effective material as it possessed both biosorption and biocidal properties. This last characteristic is corresponding to nanosilver content. The combination of these two parameters enabled better attraction of bacteria cells to the surface of the $\mathrm{RGO} / \mathrm{Al}_{2} \mathrm{O}_{3}-\mathrm{Ag}$ nanocomposite and their subsequent complete deactivation. The already made effort is a great step forward development of complex GFM-based structures. On the other hand, more research is needed to further confirm the applicability of these innovative materials in larger scale, up to the industrial practice.

\section{REFERENCES}

Ahmadi, N., Nemati, A., and Bagherzadeh, M. (2018). Synthesis and Properties of Ce-Doped TiO2-Reduced Graphene Oxide Nanocomposite. J. Alloys Comp. 742, 986-995. doi:10.1016/j.jallcom.2018.01.105

Akhavan, O., and Ghaderi, E. (2012). Escherichia coli Bacteria Reduce Graphene Oxide to Bactericidal Graphene in a Self-Limiting Manner. Carbon 50, 1853-1860. doi:10.1016/j.carbon.2011.12.035

Akhavan, O., and Ghaderi, E. (2010). Toxicity of Graphene and Graphene Oxide Nanowalls Against Bacteria. ACS Nano 4, 5731-5736. doi:10.1021/nn101390x

Alshammari, A. S., Halim, M. M., Yam, F. K., and Kaus, N. H. M. (2020). Synthesis of Titanium Dioxide (TiO2)/Reduced Graphene Oxide (rGO) Thin Film Composite by Spray Pyrolysis Technique and its Physical Properties. Mater. Sci. Semiconductor Process. 116, 105140. doi:10.1016/j.mssp.2020.105140

An, W., Zhang, Y., Zhang, X., Li, K., Kang, Y., Akhtar, S., et al. (2018). Ocular Toxicity of Reduced Graphene Oxide or Graphene Oxide Exposure in Mouse Eyes. Exp. Eye Res. 174, 59-69. doi:10.1016/j.exer.2018.05.024

Arvidsson, R., Boholm, M., Johansson, M., and de Montoya, M. L. (2018). “Just Carbon": Ideas about Graphene Risks by Graphene Researchers and Innovation Advisors. Nanoethics 12, 199-210. doi:10.1007/s11569-018-0324-y

Arvidsson, R., Molander, S., Sandén, B. A., and Hassellöv, M. (2011). Challenges in Exposure Modeling of Nanoparticles in Aquatic Environments. Hum. Ecol. Risk Assess. Int. J. 17, 245-262. doi:10.1080/10807039.2011.538639

Bitton, G., and Marshall, K. (1980). Adsorption of Microorganisms to Surfaces. New York, NY: Wiley, 7-58.

Bruinsma, G. M., Rustema-abbing, M., van der Mei, H. C., and Busscher, H. J. (2001). Effects of Cell Surface Damage on Surface Properties and Adhesion of Pseudomonas aeruginosa. J. Microbiol. Methods 45, 95-101. doi:10.1016/s01677012(01)00238-x

Castro Neto, A. H., Guinea, F., Peres, N. M. R., Novoselov, K. S., and Geim, A. K. (2009). The Electronic Properties of Graphene. Rev. Mod. Phys. 81, 109-162. doi:10.1103/RevModPhys.81.109

Chang, B. Y., Huang, N. M., An'amt, M. N., Marlinda, A. R., Norazriena, Y., Muhamad, M. R., et al. (2012). Facile Hydrothermal Preparation of Titanium Dioxide Decorated Reduced Graphene Oxide Nanocomposite. Int. J. Nanomedicine 7, 3379-3387. doi:10.2147/IJN.S28189

Chen, S., Su, Y., Fan, H., Song, J., Hu, T., Hu, L., et al. (2021). Friction and Wear Behavior of Al2O3/rGO Fibrous Monolithic Ceramics with Bamboo like Architectures. Tribology Int. 155, 106805. doi:10.1016/ j.triboint.2020.106805

Chen, S., Su, Y., Song, J., Fan, H., Jiang, X., Hu, L., et al. (2020a). Bioinspired Alumina/reduced Graphene Oxide Fibrous Monolithic Ceramic and its Fracture Responses. J. Am. Ceram. Soc. 103, 3826-3836. doi:10.1111/jace.17039

Chen, Y.-S., Chao, B.-K., Nagao, T., and Hsueh, C.-H. (2020b). Effects of Ag Particle Geometry on Photocatalytic Performance of Ag/TiO2/reduced Graphene Oxide Ternary Systems. Mater. Chem. Phys. 240, 122216. doi:10.1016/j.matchemphys.2019.122216

Chook, S. W., Chia, C. H., Zakaria, S., Ayob, M. K., Chee, K. L., Neoh, H. M., et al. (2012). Silver Nanoparticles - Graphene Oxide Nanocomposite for Antibacterial Purpose. Adv. Mater. Res. 364, 439-443. doi:10.4028/ www.scientific.net/AMR

\section{AUTHOR CONTRIBUTIONS}

MJ analyzed the state of the art regarding materials' synthesis methods, biological activities, and toxicity; AJ wrote, edited, and reviewed the original draft. All authors contributed to the article and approved the submitted version of the paper.

\section{FUNDING}

This research was funded by The National Science Centre, grant 'Sonata bis 7' number UMO-2017/26/E/ST8/01073.

Cygan, T., Wozniak, J., Kostecki, M., Petrus, M., Jastrzębska, A., Ziemkowska, W., et al. (2017). Mechanical Properties of Graphene Oxide Reinforced Alumina Matrix Composites. Ceramics Int. 43, 6180-6186. doi:10.1016/ j.ceramint.2017.02.015

Dalai, S., Pakrashi, S., Bhuvaneshwari, M., Iswarya, V., Chandrasekaran, N., and Mukherjee, A. (2014). Toxic Effect of $\mathrm{Cr}(\mathrm{VI})$ in Presence of $\mathrm{N}-\mathrm{TiO} 2$ and N-Al2O3 Particles towards Freshwater Microalgae. Aquat. Toxicol. 146, $28-37$. doi:10.1016/j.aquatox.2013.10.029

Dargahi, Z., Asgharzadeh, H., and Maleki-Ghaleh, H. (2018). Synthesis of MoDoped TiO2/reduced Graphene Oxide Nanocomposite for Photoelectrocatalytic Applications. Ceramics Int. 44, 13015-13023. doi:10.1016/j.ceramint.2018.04.120

Dikusar, M. M. (1940). Adsorption of Bacteria and its Effect on Microbial Processes. Mikrobiologiya 9, 895-908.

Dundar, I., Mere, A., Mikli, V., Krunks, M., and Oja Acik, I. (2020). Thickness Effect on Photocatalytic Activity of Tio2 Thin Films Fabricated by Ultrasonic Spray Pyrolysis. Catalysts 10, 1-13. doi:10.3390/catal10091058

Ellwood, D. C., Keevil, C. W., Marsh, P. D., Brown, C. M., and Wardell, J. N. (1982). Surface-associated Growth. Philos. Trans. R. Soc. Lond. B. Biol. Sci. 297, 517-532. doi:10.1098/rstb.1982.0058

Fan, W., Lai, Q., Zhang, Q., and Wang, Y. (2011). Nanocomposites of TiO2 and Reduced Graphene Oxide as Efficient Photocatalysts for Hydrogen Evolution. J. Phys. Chem. C 115, 10694-10701. doi:10.1021/jp2008804

Fletcher, M., and Loeb, G. I. (1979). Influence of Substratum Characteristics on the Attachment of a Marine Pseudomonad to Solid Surfaces. Appl. Environ. Microbiol. 37, 67-72. doi:10.1128/aem.37.1.67-72.1979

Fonte, E. S., Amado, A. M., Meirelles-Pereira, F., Esteves, F. A., Rosado, A. S., and Farjalla, V. F. (2013). The Combination of Different Carbon Sources Enhances Bacterial Growth Efficiency in Aquatic Ecosystems. Microb. Ecol. 66, 871-878. doi:10.1007/s00248-013-0277-1

Frank, I. W., Tanenbaum, D. M., van der Zande, A. M., and McEuen, P. L. (2007). Mechanical Properties of Suspended Graphene Sheets. J. Vac. Sci. Technol. B 25, 2558. doi:10.1116/1.2789446

Gannon, J., Tan, Y. H., Baveye, P., and Alexander, M. (1991). Effect of Sodium Chloride on Transport of Bacteria in a Saturated Aquifer Material. Appl. Environ. Microbiol. 57, 2497-2501. doi:10.1128/aem.57.9.2497-2501.1991

Garg, B., Bisht, T., and Ling, Y.-C. (2014). Graphene-based Nanomaterials as Heterogeneous Acid Catalysts: A Comprehensive Perspective. Molecules 19, 14582-14614. doi:10.3390/molecules 190914582

Gomez, J., Villaro, E., Karagiannidis, P. G., and Elmarakbi, A. (2020). Effects of Chemical Structure and Morphology of Graphene-Related Materials (GRMs) on Melt Processing and Properties of GRM/polyamide-6 Nanocomposites. Results Mater. 7, 100105. doi:10.1016/j.rinma.2020.100105

Guan, S., Hao, L., Yoshida, H., Itoi, T., Cheng, Y., Seki, S., et al. (2021). Enhanced Photocatalytic Activity and Stability of TiO2/graphene Oxide Composites Coatings by Electrophoresis Deposition. Mater. Lett. 286, 129258. doi:10.1016/j.matlet.2020.129258

Guo, J., Zhu, S., Chen, Z., Li, Y., Yu, Z., Liu, Q., et al. (2011). Sonochemical Synthesis of $\mathrm{TiO} 2$ Nanoparticles on Graphene for Use as Photocatalyst. Ultrason. Sonochem. 18, 1082-1090. doi:10.1016/j.ultsonch.2011.03.021

Gurunathan, S., Woong Han, J., Abdal Daye, A., Eppakayala, V., and Kim, J.-h. (2012). Oxidative Stress-Mediated Antibacterial Activity of Graphene Oxide 
and Reduced Graphene Oxide in Pseudomonas aeruginosa. Ijn 7, 5901-5914. doi:10.2147/IJN.S37397

He, T., Li, J., Wang, L., Zhu, J., and Jiang, W. (2009). Preparation and Consolidation of Alumina/graphene Composite Powders. Mater. Trans. 50, 749-751. doi:10.2320/matertrans.MRA2008458

Hu, J., Zhang, Z., Zhang, C., Liu, S., Zhang, H., Li, D., et al. (2018). Al2O3 Nanoparticle Impact on the Toxic Effect of $\mathrm{Pb}$ on the Marine Microalga Isochrysis Galbana. Ecotoxicology Environ. Saf. 161, 92-98. doi:10.1016/ j.ecoenv.2018.05.090

Hu, W., Peng, C., Luo, W., Lv, M., Li, X., Li, D., et al. (2010). Graphene-based Antibacterial Paper. ACS Nano 4, 4317-4323. doi:10.1021/nn101097v

Huysman, F., and Verstraete, W. (1993). Water-facilitated Transport of Bacteria in Unsaturated Soil Columns: Influence of Cell Surface Hydrophobicity and Soil Properties. Soil Biol. Biochem. 25, 83-90. doi:10.1016/0038-0717(93) 90245-7

Ikram, M., Tao, Z., Ye, J., Qayyum, H. A., Sun, X., and Xu, J. (2018). Enhanced Physical Properties of $\gamma$-Al2O3-rGO Hybrids Prepared by Solvothermal and Hot-Press Processing. RSC Adv. 8, 8329-8337. doi:10.1039/c8ra00095f

Jahnel, J. (2015). "Addressing the Challenges to the Risk Assessment of Nanomaterials," in Nanoengineering. Global Approaches to Health and Safety Issues. Editors P. I. Dolez (Amsterdam, Netherlands: Elsevier B.V.), 485-521. doi:10.1016/B978-0-444-62747-6.00015-4

Jakubczak, M., Karwowska, E., Fiedorczuk, A., and Jastrzębska, A. M. (2021). Multifunctional Carbon-Supported Bioactive Hybrid Nanocomposite (C/GO/ NCP) Bed for superior Water Decontamination from Waterborne Microorganisms. RSC Adv. 11, 18509-18518. doi:10.1039/d1ra02315b

Jastrzębska, A. M., Karcz, J., Karwowska, E., Fiedorczuk, A., and Olszyna, A. (2016). Synthesis and Bioactivity of Reduced Graphene Oxide/Alumina-Noble Metal Nanocomposite Flakes. Int. J. Appl. Ceram. Technol. 13, 856-870. doi:10.1111/ijac.12555

Jastrzebska, A. M., Karcz, J., Karwowska, E., Fiedorczuk, A., and Olszyna, A. (2017d). Synthesis and Bioactivity of RGO/TiO2-noble Metal Nanocomposite Flakes. J. Nano Res. 47, 33-48. doi:10.4028/www.scientific.net/

Jastrzębska, A. M., Karcz, J., Karwowska, E., and Olszyna, A. (2017e). Biosorption Properties of RGO/Al2O3 Nanocomposite Flakes Modified with Ag, Au, and Pd for Water Purification. J. Alloys Compd. 724, 869-878. doi:10.1016/ j.jallcom.2017.07.056

Jastrzebska, A. M., Karcz, J., Letmanowski, R., Zabost, D., Ciecierska, E., Siekierski, M., et al. (2016). Synthesis of RGO/TiO2 Nanocomposite Flakes and Characterization of Their Unique Electrostatic Properties Using Zeta Potential Measurements. J. Alloys Compd. 679, 470-484. doi:10.1016/ j.jallcom.2016.04.043

Jastrzębska, A. M., Karcz, J., Letmanowski, R., Zabost, D., Ciecierska, E., Zdunek, J., et al. (2016a). Synthesis of the RGO/Al2O3 Core-Shell Nanocomposite Flakes and Characterization of Their Unique Electrostatic Properties Using Zeta Potential Measurements. Appl. Surf. Sci. 362, 577-594. doi:10.1016/ j.apsusc.2015.10.125

Jastrzębska, A. M., Kurtycz, P., and Olszyna, A. R. (2012). Recent Advances in Graphene Family Materials Toxicity Investigations. J. Nanoparticle Res. 14, 1320. doi:10.1007/s11051-012-1320-8

Jastrzębska, A. M., Olszyna, A. R., Jureczko, J., and Kunicki, A. (2015). New Reduced Graphene Oxide/alumina (RGO/Al2O3) Nanocomposite: Innovative Method of Synthesis and Characterization. Int. J. Appl. Ceram. Technol. 12, 522-528. doi:10.1111/ijac.12183

Jastrzębska, A. M., and Olszyna, A. R. (2015). The Ecotoxicity of Graphene Family Materials: Current Status, Knowledge Gaps and Future Needs. J. Nanoparticle Res. 17, 1-21. doi:10.1007/s11051-014-2817-0

Jastrzębska, A., Derecka, A., Karwowska, E., Plạsek, A., Wojciechowski, T., Ziemkowska, W., et al. (2017c). Comparative Assessment of Biocidal Activity of Different RGO/ceramic Oxide-Ag Nanocomposites. J. Nano Res. 47, 89-95. doi:10.4028/www.scientific.net/

Jastrzębska, A. M., Jureczko, J., Karcz, J., Kunicki, A., Ziemkowska, W., and Olszyna, A. (2017b). Controlled Synthesis of Graphene Oxide/alumina Nanocomposites Using a New Dry Sol-Gel Method of Synthesis. Chem. Pap. 71, 579-595. doi:10.1007/s11696-016-0040-4

Jastrzębska, A. M., Karwowska, E., Kostecki, M., and Olszyna, A. R. (2017a). Bacterial Adsorption with Graphene Family Materials Compared to NanoAlumina. Main Gr. Chem. 16, 175-190. doi:10.3233/MGC-160217
Jin, S., Yang, Y., Zhang, J., and Zheng, H. (2021). Preparation of a Novel TiO2Graphene 3D Framework Material for Efficient Adsorption-Photocatalytic Removal of Micro-organic Contaminants from Water. Mater. Chem. Phys. 263, 124339. doi:10.1016/j.matchemphys.2021.124339

Jiwei, T., Yunqi, L. I. U., Shuang, T., Dandan, L. I. U., and Chenguang, L. I. U. (1987). Fabrication of Alumina / Graphene Composite and its Catalytic Application Property in the Selective Hydrodesulfurization of FCC Gasoline Oil. 中国科技论文在线

Katsumiti, A., Tomovska, R., and Cajaraville, M. P. (2017). Intracellular Localization and Toxicity of Graphene Oxide and Reduced Graphene Oxide Nanoplatelets to Mussel Hemocytes In Vitro. Aquat. Toxicol. 188, 138-147. doi:10.1016/j.aquatox.2017.04.016

Keller, A. A., Wang, H., Zhou, D., Lenihan, H. S., Cherr, G., Cardinale, B. J., et al. (2010). Stability and Aggregation of Metal Oxide Nanoparticles in Natural Aqueous Matrices. Environ. Sci. Technol. 44, 1962-1967. doi:10.1021/ es902987d

Kim, D., Kang, H., Bae, D., Nam, S., Quevedo-Lopez, M., and Choi, H. (2018). Synthesis of Reduced Graphene Oxide/aluminum Nanocomposites Via Chemical-Mechanical Processes. J. Compos. Mater. 52, 3015-3025. doi:10.1177/0021998318760152

Krekeler, C., Ziehr, H., and Klein, J. (1991). Influence of Physicochemical Bacterial Surface Properties on Adsorption to Inorganic Porous Supports. Appl. Microbiol. Biotechnol. 35, 484-490. doi:10.1007/BF00169754

Kucinskis, G., Bajars, G., and Kleperis, J. (2013). Graphene in Lithium Ion Battery Cathode Materials: A Review. J. Power Sourc. 240, 66-79. doi:10.1016/ j.jpowsour.2013.03.160

Kumar, K. D., Kumar, G. P., and Reddy, K. S. (2015). Rapid Microwave Synthesis of Reduced Graphene Oxide-Supported TiO2 Nanostructures as High Performance Photocatalyst. Mater. Today Proc. 2, 3736-3742. doi:10.1016/ j.matpr.2015.07.204

Kurantowicz, N., Sawosz, E., Jaworski, S., Kutwin, M., Strojny, B., Wierzbicki, M., et al. (2015). Interaction of Graphene Family Materials with Listeria Monocytogenes and Salmonella enterica. Nanoscale Res. Lett. 10, 1-12. doi:10.1186/s11671-015-0749-y

Kłodzińska, E., Szumski, M., Dziubakiewicz, E., Hrynkiewicz, K., Skwarek, E., Janusz, W., et al. (2010). Effect of Zeta Potential Value on Bacterial Behavior during Electrophoretic Separation. Electrophoresis 31, 1590-1596. doi:10.1002/ elps.200900559

Li, D., Müller, M. B., Gilje, S., Kaner, R. B., and Wallace, G. G. (2008). Processable Aqueous Dispersions of Graphene Nanosheets. Nat. Nanotech 3, 101-105. doi:10.1038/nnano.2007.451

Li, Q.-L., Yuan, D.-X., and Lin, Q.-M. (2004). Evaluation of Multi-Walled Carbon Nanotubes as an Adsorbent for Trapping Volatile Organic Compounds from Environmental Samples. J. Chromatogr. A 1026, 283-288. doi:10.1016/ j.chroma.2003.10.109

Li, Y.-H., Ding, J., Luan, Z., Di, Z., Zhu, Y., Xu, C., et al. (2003). Competitive Adsorption of $\mathrm{Pb} 2+, \mathrm{Cu} 2+$ and $\mathrm{Cd} 2+$ Ions from Aqueous Solutions by Multiwalled Carbon Nanotubes. Carbon 41, 2787-2792. doi:10.1016/S00086223(03)00392-0

Liang, Y., Wang, H., Sanchez Casalongue, H., Chen, Z., and Dai, H. (2010). TiO2 Nanocrystals Grown on Graphene as Advanced Photocatalytic Hybrid Materials. Nano Res. 3, 701-705. doi:10.1007/s12274-010-0033-5

Liu, L., Bai, H., Liu, J., and Sun, D. D. (2013). Multifunctional Graphene OxideTiO2-Ag Nanocomposites for High Performance Water Disinfection and Decontamination Under Solar Irradiation. J. Hazard. Mater. 261, 214-223. doi:10.1016/j.jhazmat.2013.07.034

Liu, S., Zeng, T. H., Hofmann, M., Burcombe, E., Wei, J., Jiang, R., et al. (2011). Antibacterial Activity of Graphite, Graphite Oxide, Graphene Oxide, and Reduced Graphene Oxide: Membrane and Oxidative Stress. ACS Nano 5, 6971-6980. doi:10.1021/nn202451x

Liu, X. T., Mu, X. Y., Wu, X. L., Meng, L. X., Guan, W. B., Ma, Y. Q., et al. (2014). Toxicity of Multi-Walled Carbon Nanotubes, Graphene Oxide, and Reduced Graphene Oxide to Zebrafish Embryos. Biomed. Environ. Sci. 27, 676-683. doi:10.3967/bes2014.103

Liu, Y., Zhang, Z., and Hu, R. (2018). Synthesis of Three-Dimensional Hierarchically Porous Reduced Graphene Oxide-TiO2 Nanocomposite for Enhanced Hydrogen Storage. Ceramics Int. 44, 12458-12465. doi:10.1016/ j.ceramint.2018.04.036 
Mangun, C. L., Yue, Z., Economy, J., Maloney, S., Kemme, P., and Cropek, D. (2001). Adsorption of Organic Contaminants from Water Using Tailored ACFs. Chem. Mater. 13, 2356-2360. doi:10.1021/cm000880g

Markandan, K., Chin, J. K., and Tan, M. T. T. (2017). Recent Progress in Graphene Based Ceramic Composites: A Review. J. Mater. Res. 32, 84-106. doi:10.1557/ jmr.2016.390

Marshall, K. C. (1992). Biofilms an Overview of Bacterial Adhesion, Activity and Control at Surfaces. ASM News 58, 202-207.

Marshall, K. C., Stout, R., and Mitchell, R. (1971). Mechanism of the Initial Events in the Sorption of Marine Bacteria to Surfaces. J. Gen. Microbiol. 68, 337-348. doi:10.1099/00221287-68-3-337

Martinez-Martinez, L., Pascual, A., and Perea, E. J. (1991). Kinetics of Adherence of Mucoid and Non-mucoid Pseudomonas aeruginosa to Plastic Catheters. J. Med. Microbiol. 34, 7-12. doi:10.1099/00222615-34-1-7

McWilliams, A. (2013). Graphene: Technologies, Applications and Markets, Market Forecasting. Available at: https://www.bccresearch.com/marketresearch/advanced-materials/graphene-technologies-applications-marketsreport.html (Accessed March 23, 2021).

Mikolajczyk, A., Gajewicz, A., Rasulev, B., Schaeublin, N., Maurer-Gardner, E., Hussain, S., et al. (2015). Zeta Potential for Metal Oxide Nanoparticles: A Predictive Model Developed by a Nano-Quantitative Structure-Property Relationship Approach. Chem. Mater. 27, 2400-2407. doi:10.1021/ cm504406a

Mozes, N., Marchal, F., Hermesse, M. P., Van Haecht, J. L., Reuliaux, L., Leonard, A. J., et al. (1987). Immobilization of Microorganisms by Adhesion: Interplay of Electrostatic and Nonelectrostatic Interactions. Biotechnol. Bioeng. 30, 439-450. doi:10.1002/bit.260300315

Muszynski, R., Seger, B., and Kamat, P. V. (2008). Decorating Graphene Sheets with Gold Nanoparticles. J. Phys. Chem. C 112, 5263-5266. doi:10.1021/ jp800977b

Neto, A. C., Guinea, F., and Peres, N. M. (2006). Drawing Conclusions from Graphene. Phys. World 19, 33-37. doi:10.1088/2058-7058/19/11/34

Novoselov, K. S., Geim, A. K., Morozov, S. V., Jiang, D., Zhang, Y., Dubonos, S. V., et al. (2004). Electric Field Effect in Atomically Thin Carbon Films. Science 306, 666-669. doi:10.1126/science.1102896

Olborska, A., Janas-Naze, A., Kaczmarek, Ł., Warga, T., and Che Halin, D. S. (2020). Antibacterial Effect of Graphene and Graphene Oxide as a Potential Material for Fiber Finishes. Autex Res. J. 20, 506-516. doi:10.2478/aut-20200009

Olowoyo, J. O., Kumar, M., Singh, B., Oninla, V. O., Babalola, J. O., Valdés, H., et al. (2019). Self-assembled Reduced Graphene Oxide-TiO2 Nanocomposites: Synthesis, DFTB+ Calculations, and Enhanced Photocatalytic Reduction of CO2 to Methanol. Carbon 147, 385-397. doi:10.1016/j.carbon.2019.03.019

Ominato, Y., and Koshino, M. (2013). Orbital Magnetism of Graphene Nanostructures. Solid State. Commun. 175-176, 51-61. doi:10.1016/ j.ssc.2013.09.023

Pallecchi, E., Lafont, F., Cavaliere, V., Schopfer, F., Mailly, D., Poirier, W., et al. (2014). High Electron Mobility in Epitaxial Graphene on $4 \mathrm{H}-\mathrm{SiC}(0001) \mathrm{Via}$ Post-growth Annealing Under Hydrogen. Sci. Rep. 4, 1-7. doi:10.1038/ srep04558

Peng, X., Luan, Z., Ding, J., Di, Z., Li, Y., and Tian, B. (2005). Ceria Nanoparticles Supported on Carbon Nanotubes for the Removal of Arsenate From Water. Mater. Lett. 59, 399-403. doi:10.1016/j.matlet.2004.05.090

Peralta-Videa, J. R., Zhao, L., Lopez-Moreno, M. L., de la Rosa, G., Hong, J., and Gardea-Torresdey, J. L. (2011). Nanomaterials and the Environment: A Review for the Biennium 2008-2010. J. Hazard. Mater. 186, 1-15. doi:10.1016/ j.jhazmat.2010.11.020

Peter, A., Mihaly-Cozmuta, L., Mihaly-Cozmuta, A., Nicula, C., Jastrzębska, A., Kurtycz, P., et al. (2015). Morphology, Structure, and Photoactivity of Two Types of Graphene Oxide-TiO2 Composites. Chem. Pap. 69, 839-855. doi:10.1515/chempap-2015-0088

Petrone, N., Meric, I., Hone, J., and Shepard, K. L. (2013). Graphene Field-Effect Transistors with Gigahertz-Frequency Power Gain on Flexible Substrates. Nano Lett. 13, 121-125. doi:10.1021/nl303666m

Pop, E., Varshney, V., and Roy, A. K. (2012). Thermal Properties of Graphene: Fundamentals and Applications. MRS Bull. 37, 1273-1281. doi:10.1557/ mrs.2012.203
Pugazhenthiran, N., Mangalaraja, R. V., Vijaya, S., Suresh, S., Kandasamy, M., Sathishkumar, P., et al. (2020). Fluorine-free Synthesis of Reduced Graphene Oxide Modified Anatase TiO2 Nanoflowers Photoanode with Highly Exposed

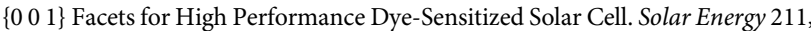
1017-1026. doi:10.1016/j.solener.2020.10.008

Radic, S., Geitner, N. K., Podila, R., Käkinen, A., Chen, P., Ke, P. C., et al. (2013). Competitive Binding of Natural Amphiphiles with Graphene Derivatives. Sci. Rep. 3, 1-8. doi:10.1038/srep02273

Ramírez, C., Belmonte, M., Miranzo, P., and Osendi, M. I. (2021). Applications of Ceramic/graphene Composites and Hybrids. Materials 14, 2071. doi:10.3390/ ma14082071

Sadoun, A. M., and Fathy, A. (2019). Experimental Study on Tribological Properties of $\mathrm{Cu}-\mathrm{Al} 2 \mathrm{O} 3$ Nanocomposite Hybridized by Graphene Nanoplatelets. Ceramics Int. 45, 24784-24792. doi:10.1016/ j.ceramint.2019.08.220

Sangjan, S., Wisasa, K., and Deddeaw, N. (2019). Enhanced Photodegradation of Reactive Blue Dye Using Ga and Gd as Catalyst in Reduced Graphene OxideBased TiO2 Composites. Mater. Today Proc. 6, 19-23. doi:10.1016/ j.matpr.2018.05.071

Santoro, T., and Stotzky, G. (1968). Sorption between Microorganisms and clay Minerals as Determined by the Electrical Sensing Zone Particle Analyzer. Can. J. Microbiol. 14, 299-307. doi:10.1139/m68-049

Sarikaya, S., Henry, T. C., and Naraghi, M. (2020). Graphene Size and Morphology: Peculiar Effects on Damping Properties of Polymer Nanocomposites. Exp. Mech. 60, 753-762. doi:10.1007/s11340-020-00592-7

Scholl, M. A., Mills, A. L., Herman, J. S., and Hornberger, G. M. (1990). The Influence of Mineralogy and Solution Chemistry on the Attachment of Bacteria to Representative Aquifer Materials. J. Contaminant Hydrol. 6, 321-336. doi:10.1016/0169-7722(90)90032-C

Shao, Y., Wang, J., Wu, H., Liu, J., Aksay, I. A., and Lin, Y. (2010). Graphene Based Electrochemical Sensors and Biosensors: A Review. Electroanalysis 22, 1027-1036. doi:10.1002/elan.200900571

Shen, X., Wu, J., Bai, S., and Zhou, H. (2010). One-pot Solvothermal Syntheses and Magnetic Properties of Graphene-Based Magnetic Nanocomposites. J. Alloys Comp. 506, 136-140. doi:10.1016/j.jallcom.2010.06.158

Song, L., Khoerunnisa, F., Gao, W., Dou, W., Hayashi, T., Kaneko, K., et al. (2013). Effect of High-Temperature thermal Treatment on the Structure and Adsorption Properties of Reduced Graphene Oxide. Carbon 52, 608-612. doi:10.1016/j.carbon.2012.09.060

Soni, K. A., Balasubramanian, A. K., Beskok, A., and Pillai, S. D. (2008). Zeta Potential of Selected Bacteria in Drinking Water When Dead, Starved, or Exposed to Minimal and Rich Culture media. Curr. Microbiol. 56, 93-97. doi:10.1007/s00284-007-9046-Z

Stankovich, S., Dikin, D. A., Piner, R. D., Kohlhaas, K. A., Kleinhammes, A., Jia, Y., et al. (2007). Synthesis of Graphene-Based Nanosheets Via Chemical Reduction of Exfoliated Graphite Oxide. Carbon 45, 1558-1565. doi:10.1016/ j.carbon.2007.02.034

Stankovich, S., Piner, R. D., Chen, X., Wu, N., Nguyen, S. T., and Ruoff, R. S. (2006). Stable Aqueous Dispersions of Graphitic Nanoplatelets via the Reduction of Exfoliated Graphite Oxide in the Presence of Poly(sodium 4-styrenesulfonate). J. Mater. Chem. 16, 155-158. doi:10.1039/b512799h

Tismanar, I., Obreja, A. C., Buiu, O., and Duta, A. (2021). VIS-active TiO2 Graphene Oxide Composite Thin Films for Photocatalytic Applications. Appl. Surf. Sci. 538, 147833. doi:10.1016/j.apsusc.2020.147833

van Loosdrecht, M. C., Lyklema, J., Norde, W., Schraa, G., and Zehnder, A. J. (1987). Electrophoretic Mobility and Hydrophobicity as a Measured to Predict the Initial Steps of Bacterial Adhesion. Appl. Environ. Microbiol. 53, 1898-1901. doi:10.1128/aem.53.8.1898-1901.1987

Vasilaki, E., Georgaki, I., Vernardou, D., Vamvakaki, M., and Katsarakis, N. (2015). Ag-loaded TiO2/reduced Graphene Oxide Nanocomposites for Enhanced Visible-Light Photocatalytic Activity. Appl. Surf. Sci. 353, 865-872. doi:10.1016/j.apsusc.2015.07.056

Wang, G., Qian, F., Saltikov, C. W., Jiao, Y., and Li, Y. (2011). Microbial Reduction of Graphene Oxide by Shewanella. Nano Res. 4, 563-570. doi:10.1007/s12274011-0112-2

Wang, G., Wang, B., Wang, X., Park, J., Dou, S., Ahn, H., et al. (2009b). Sn/ graphene Nanocomposite with 3D Architecture for Enhanced Reversible 
Lithium Storage in Lithium Ion Batteries. J. Mater. Chem. 19, 8378-8384. doi:10.1039/b914650d

Wang, H., Wick, R. L., and Xing, B. (2009a). Toxicity of Nanoparticulate and Bulk $\mathrm{ZnO}, \mathrm{Al} 2 \mathrm{O} 3$ and $\mathrm{TiO} 2$ to the Nematode Caenorhabditis elegans. Environ. Pollut. 157, 1171-1177. doi:10.1016/j.envpol.2008.11.004

Wang, S., Chia, P.-J., Chua, L.-L., Zhao, L.-H., Png, R.-Q., Sivaramakrishnan, S., et al. (2008). Band-like Transport in Surface-Functionalized Highly Solution-Processable Graphene Nanosheets. Adv. Mater. 20, 3440-3446. doi:10.1002/adma.200800279

Wang, S., Sun, H., Ang, H. M., and Tadé, M. O. (2013). Adsorptive Remediation of Environmental Pollutants Using Novel Graphene-Based Nanomaterials. Chem. Eng. J. 226, 336-347. doi:10.1016/j.cej.2013.04.070

Watcharotone, S., Dikin, D. A., Stankovich, S., Piner, R., Jung, I., Dommett, G. H. B., et al. (2007). Graphene-Silica Composite Thin Films as Transparent Conductors. Nano Lett. 7, 1888-1892. doi:10.1021/nl070477+

Williams, G., Seger, B., and Kamat, P. V. (2008). TiO2-Graphene Nanocomposites. UV-Assisted Photocatalytic Reduction of Graphene Oxide. ACS Nano 2, 1487-1491. doi:10.1021/nn800251f

Wozniak, J., Jastrzębska, A., Cygan, T., and Olszyna, A. (2017). Surface Modification of Graphene Oxide Nanoplatelets and its Influence on Mechanical Properties of Alumina Matrix Composites. J. Eur. Ceram. Soc. 37, 1587-1592. doi:10.1016/j.jeurceramsoc.2016.11.010

Wu, J., Shen, X., Jiang, L., Wang, K., and Chen, K. (2010). Solvothermal Synthesis and Characterization of sandwich-like graphene/ZnO Nanocomposites. Appl. Surf. Sci. 256, 2826-2830. doi:10.1016/j.apsusc.2009.11.034

Xu, C., Wang, X., and Zhu, J. (2008). Graphene-Metal Particle Nanocomposites. J. Phys. Chem. C 112, 19841-19845. doi:10.1021/jp807989b

Yang, X., Qin, J., Jiang, Y., Chen, K., Yan, X., Zhang, D., et al. (2015). Fabrication of P25/Ag3PO4/graphene Oxide Heterostructures for Enhanced Solar Photocatalytic Degradation of Organic Pollutants and Bacteria. Appl. Catal. B: Environ. 166-167, 231-240. doi:10.1016/j.apcatb.2014.11.028

Yang, Y., Liu, M., Han, S., Xi, H., Xu, C., Yuan, R., et al. (2021). Double-sided Modification of $\mathrm{TiO} 2$ Spherical Shell by Graphene Sheets with Enhanced Photocatalytic Activity for CO2 Reduction. Appl. Surf. Sci. 537, 147991. doi:10.1016/j.apsusc.2020.147991

Yantasee, W., Lin, Y., Fryxell, G. E., Busche, B. J., and Birnbaum, J. C. (2003). Removal of Heavy Metals from Aqueous Solution Using Novel Nanoengineered Sorbents: Self-Assembled Carbamoylphosphonic Acids on Mesoporous Silica. Separat. Sci. Tech. 38, 3809-3825. doi:10.1081/SS-120024232

Yin, J., Dong, Z., Liu, Y., Wang, H., Li, A., Zhuo, Z., et al. (2020). Toxicity of Reduced Graphene Oxide Modified by Metals in Microalgae: Effect of the
Surface Properties of Algal Cells and Nanomaterials. Carbon 169, 182-192. doi:10.1016/j.carbon.2020.07.057

Yin, Z., Zhu, J., He, Q., Cao, X., Tan, C., Chen, H., et al. (2014). Graphene-Based Materials for Solar Cell Applications. Adv. Energ. Mater. 4, 1300574. doi:10.1002/aenm.201300574

Załęska-Radziwiłł, M., Doskocz, N., Affek, K., and Muszyński, A. (2020). Effect of Aluminum Oxide Nanoparticles on Aquatic Organisms - A Microcosm Study. Desalin. Water Treat. 195, 286-296. doi:10.5004/ dwt.2020.25882

Zhang, H., Han, X., and Zhao, Y. (2017). Pd-TiO 2 Nanoparticles Supported on Reduced Graphene Oxide: Green Synthesis and Improved Electrocatalytic Performance for Methanol Oxidation. J. Electroanalytical Chem. 799, 84-91. doi:10.1016/j.jelechem.2017.05.026

Zhang, H., Shuang, S., Wang, G., Guo, Y., Tong, X., Yang, P., et al. (2015). TiO2graphene Hybrid Nanostructures by Atomic Layer Deposition with Enhanced Electrochemical Performance for $\mathrm{Pb}(\mathrm{II})$ and $\mathrm{Cd}(\mathrm{II})$ Detection. RSC Adv. 5, 4343-4349. doi:10.1039/c4ra09779c

Zhang, H., Xu, P., Du, G., Chen, Z., Oh, K., Pan, D., et al. (2011b). A Facile Onestep Synthesis of TiO2/graphene Composites for Photodegradation of Methyl Orange. Nano Res. 4, 274-283. doi:10.1007/s12274-010-0079-4

Zhang, Y., Mo, G., Li, X., Zhang, W., Zhang, J., Ye, J., et al. (2011a). A Graphene Modified Anode to Improve the Performance of Microbial Fuel Cells. J. Power Sourc. 196, 5402-5407. doi:10.1016/j.jpowsour.2011.02.067

Zhang, Y., Tang, Z.-R., Fu, X., and Xu, Y.-J. (2010). TiO2-Graphene Nanocomposites for Gas-phase Photocatalytic Degradation of Volatile Aromatic Pollutant: Is TiO2-Graphene Truly Different from Other TiO2-Carbon Composite Materials? ACS Nano 4, 7303-7314. doi:10.1021/ nn1024219

Conflict of Interest: The authors declare that the research was conducted in the absence of any commercial or financial relationships that could be construed as a potential conflict of interest.

Copyright (c) 2021 Jakubczak and Jastrzębska. This is an open-access article distributed under the terms of the Creative Commons Attribution License (CC $B Y$ ). The use, distribution or reproduction in other forums is permitted, provided the original author(s) and the copyright owner(s) are credited and that the original publication in this journal is cited, in accordance with accepted academic practice. No use, distribution or reproduction is permitted which does not comply with these terms. 